\title{
Generation of BIM models for Cultural Heritage
}

\author{
Facundo José López ${ }^{1}$, Pedro M. Lerones², José Llamas ${ }^{3}$, \\ Jaime Gómez-García-Bermejo ${ }^{4}(*)$, Eduardo Zalama ${ }^{5}$ \\ ${ }^{1}$ DISA. University of Valladolid, Valladolid (Spain).
}

Tel: (int)+983.423.355 Fax: (int)+983.423.310 Email: Arq.LopezFacundo@gmail.com

${ }^{2}$ Cartif Foundation, Parque Tecnológico de Boecillo, Valladolid (Spain).

Tel: (int)+983.546.504 Fax: (int)+983.546.521 Email: pedler@cartif.es

${ }^{3}$ Cartif Foundation, Parque Tecnológico de Boecillo, Valladolid (Spain).

Tel: (int)+983.546.504 Fax: (int)+983.546.521 Email: joslla@cartif.es

${ }^{4}$ ITAP. University of Valladolid, Valladolid (Spain).

Tel: (int)+983.423.355 Fax: (int)+983.423.310 Email: jaigom@eii.uva.es

${ }^{5}$ ITAP. University of Valladolid, Valladolid (Spain).

Tel: (int)+983.423.355 Fax: (int)+983.423.310 Email: ezalama@eii.uva.es

${ }^{(*)}$ Corresponding author: jaigom@eii.uva.es 


\section{Abstract}

In this paper, a new approach for the virtual modeling and reconstruction of Architectural Heritage is presented. The graphic and semantic information required to determine the conservation status of the analyzed buildings, obtained from point clouds and historical and bibliographical data, are combined. The modeled components are used to create a library of parametric elements under the concept of Heritage Building Information Modeling (HBIM). This represents a solution for the 3D modeling of a wide range of buildings in the same style, due to the flexibility of the modeled elements which can change in shape and proportions, thus adapting to new requirements. Moreover, technical documentation and quantitative and qualitative information can be produced, allowing detailed analysis in a remote and multidisciplinary way within the general framework of "Smart heritage".

Running head: Generation of BIM models for Cultural Heritage

Keywords: Cultural heritage documentation, 3D, Graphic/semantic information, HBIM, Smart heritage.

\section{Introduction}

Heritage is considered to be everything that has a universal value from the historical point of view through art or science, such as named monuments, buildings or landscapes, and can be divided into tangible or intangible (Vecco, 2010; Toldo \& Carrara, 2014). In particular, architectural heritage is threatened by environmental conditions, structural instability, increased tourism, etc. (lbañez et al.,2015).

Performing restoration or rehabilitation works on architectural heritage is often difficult. This is due to several problems, such as the lack of technical documentation and information about the status, shape or composition of the different elements (Del Giudice \& Osello, 2013; 
Tomaževič \& Lutman, 2007). Therefore, the collection, storage and processing of all kinds of information about the buildings is required to determine their current state, defects or pathologies, the architectural style and the different stages of their construction (Alsadik et al., 2013).

Nowadays, a high level of automation can be achieved through the use of 3D scanning and photogrammetry technologies, which allow the collection and further processing of spatial data to be accelerated. In particular, laser scanners provide a large amount of threedimensional data in a short time, under the form of millions of points (Fig. 1A) (GómezGarcia-Bermejo et al., 2013). Moreover, color data can also be incorporated by using digital cameras (Fig. 1B) (Lerones et al.,2014). However, handling the said amount of data requires large computational resources. Moreover, this data can only be incorporated into design software with difficulty.

In order for the point clouds to be useful, several steps should be taken, such as cleaning, filtering and softening. Moreover, the processed point clouds could be incorporated into Building Information Modeling (BIM) platforms, which have emerged in recent years as a means to integrate building design. According to (Baik et al., 2015; Logothetis et al., 2015), BIM methodology allows three-dimensional models to be generated with such parametric information as the geometric properties (2D), materiality specifications (3D), constructive programming (4D), the definition of amounts and costs (5D), sustainability of the project (6D) and their life cycle (7D), thus turning a simple graphical representation into a virtual project with real conditions (Azhar, 2011). An example of the semantic organization and parameters of a given object can be seen (Fig. 2). The properties of each constituent element can be modified by changing the numerical values in the table. Every object in a BIM environment has a particular parametric representation, so BIM platforms have the ability to import, manipulate and manage graphical and non-graphical information, as well as the semantic data describing each element in the model (Cheng et al., 2015). 
Often, when thinking about architecture, engineering or the construction industry, new construction and projects are considered. For this reason, the libraries of the BIM platforms are geared primarily for the design of new buildings. The reconstruction of cultural-historical heritage has revealed some limitations of BIM, such as the unavailability of historical parametric object libraries and the lack of tools for managing complex and irregular shapes obtained from point clouds. Moreover, obtaining parametric 3D models of the building elements from the point clouds is often a time-consuming process. Therefore, once the 3D models are created, libraries of the modeled elements should be generated, thus encapsulating the concept of Heritage Building Information Modeling (HBIM). Thus, the design process of the actual model and a wide range of buildings in the same style will become simpler, clearer and quicker.

\subsection{HBIM}

The HBIM concept was first used in (Murphy et al., 2009), from the Dublin Institute of Technology. According to (Murphy et al., 2009; Murphy et al., 2011; Dore et al., 2015), HBIM is a special library of BIM parametric objects that was created as a multidisciplinary and constantly evolving system. Generally, the HBIM library is built using the architectural historical documentation and the data obtained from the physical analysis of the building in question. The new components will allow 3D virtual models of any project with similar character and style to be generated, thus approaching a solution for reverse architecture.

The components of the HBIM library have the opportunity to develop details stored behind the surface of the objects regarding their construction methods and materials (Dore et al, 2015; Quattrini \& Baleani, 2015). This provides a better reading of architecture thanks to the semantic organization. In addition, the components of this library can be used as patrimonial visualization models, and to produce such technical documentation as floor plans, elevations, section cuts, details and perspectives in a semi-automated way. Historical analysis of the structure, energy simulations, calculating times and costs, as well as other functions, also 
become possible. All this provides the best way to manage the process of restoring the analyzed buildings. It also becomes possible to understand the heritage buildings that are not documented and to know their materials and construction techniques, observe the pathologies and assist maintenance and restoration efforts.

\subsection{Complementary research}

Several research works have combined point clouds and BIM software to meet the virtual modeling of architectural heritage. A set of instructions, rules and algorithms are proposed in (Dore \& Murphy, 2012), which are restricted to the use of a methodology that morphologically represents a unique architectural period, while several BIM-related programs are used to build 3D models that can be part of the future HBIM library.

Other authors, such as (Oreni et al, 2013; 2014; Baik et al, 2014) propose a series of steps to perform the reconstruction of a historical library of entire buildings from the use of point clouds. The inability of BIM programs to model irregular and complex surfaces is noted and the use of such specific software as Rhinocero or Bentley is proposed to model complex surfaces from the point clouds. Then, the solid objects obtained are exported to BIM software, where each element can have parametric information about the materials, conservation state etc. added, thus creating the HBIM library. One of the main disadvantages of this process is the loss of valuable information that can happen when data is exported from one program to another.

The work (Quattrini et al., 2015) defines the components to be modeled depending on their typology, hierarchy and material. Each element is modeled directly on the point cloud without using cuts or sections. Reference lines are used to mark the distances in the point clouds. Regular surfaces are modeled with the Revit software tools. Complex surfaces are created in B-Rep and the results obtained are exported to Revit. Details about the constructive parameters used to model the different elements are not given. 
Simple surfaces are modeled in (Barazzetti et al., 2015) using BIM program tools and solid objects, such as columns, walls, windows, etc. Then, the plug-in "NURBS" is used to represent the complex or organic surfaces and convert them to solid elements. This methodology can suffer from the previously mentioned disadvantage, i.e. the loss of valuable information when exporting data from one program to another.

Finally, another approach, for accurately modeling the buildings under study, is presented in (Murphy et al., 2011). A series of bibliographical studies representing proportions, rules and patterns of the different elements are used, then creating a methodology for performing cuts and sections on the point cloud. However, the said sections and cuts do not follow a logical order, thus making the precise modeling of the architectural components difficult.

\subsection{Proposed approach}

In the present paper, a methodology to convert laser or photogrammetric data into HBIM elements grouped in a library, adapted to the particular characteristics of historic buildings, is proposed. To this end, cuts, sections, views, grids and reference lines are used, which follow the norms, rules and constructive patterns analyzed in the bibliographic data corresponding to the actual historical architectonic periods. The aim is to create a faster and semi-automatic modeling of the objects from the use of point clouds. Moreover, the proposed methodology has been applied to a real case study, focusing on a monument of the Spanish Romanesque period. However, similar ideas could be applied to buildings of any other period, provided that the said instruments are adapted to the corresponding construction method, technology, typology and materials.

\section{Methodology}

The methodology proposed in the present paper consists of three main steps that are presented in (Fig. 3). Each step is analyzed in depth in the following subsections. 


\subsection{First step}

This step covers the collection of historical data, which we consider as non-graphic or semantic information, and the graphic or spatial information.

Considering that, in some cases, the information and technical documentation of old buildings are scarce or nonexistent, any historical source that describes the norms, rules, patterns and architectural proportions of the construction period that the building belongs to can be used to support the parametric object modeling (Piazza \& Riggio, 2007).

In fact, in the Romanesque architectural period (fourteenth century), the proportions of the different building elements were not fixed. Consequently, the monuments present significant differences and irregularities. However, the same general constructive approach was followed. Master builders, stonemasons, sawyers and sculptors, carried out construction work during this period, and the knowledge acquired by workers was based on the lessons their teachers gave them. Therefore, construction work was not documented technically (from the Roman Empire to the Renaissance period).

Authors such as (Serrano, 2001; Conant, 2001) describe the development and transformation of the constructive and structural characteristics of the Romanesque architectural period. The synthesis of traditional forms that allowed the creation of the great monuments in this period can be analyzed and interpreted using these works.

Other works help us to understand the proportions, rules and architectural principles characteristic of the Romanesque period (Lorente \& Francis, 2007; Kimball and Edgell, 1918; Jackson, 1920). The way the spaces of plants and elevations were organized in Romanesque monuments, according to simple geometric shapes such as the triangle, square or circle, is discussed. The relationship between these geometric figures will determine the preferred measurement patterns, distances between sections, number of sections, etc. 
A comparison between the figurative plant concerning modules and proportions obtained from (Lorente \& Francis, 2007) and the projection used in the current work is shown in (Fig. 4A). A comparison between the section of a system of repetitive modules obtained from (Kimball \& Edgell, 1918) and the projection performed in the present work can be seen in (Fig. 4B). Moreover, the said works serve as a guide to define the aesthetics and functionality of the organic or figurative forms of the ornaments that cover the constructive elements, such as some capitals or archivolts decorating the main entrance, usually following a semicircular arch. (Fig. 4C) shows a comparison between a prototype of a richly decorated arch, typical of Romanesque entrances (Jackson, 1920), and the arc used in the current work. Moreover, a critical overview of the internal and external space that characterizes Romanesque architecture, showing the gear and materials used in this period, such as stone, lime, straw, wood, ceramics, etc., is presented in (Moya, 2012),.

Another key aspect is the way the graphic or spatial information data is collected. Laser scanners can provide a point cloud that spatially demonstrates the visible parts of the (internal and external) surfaces of a building. The process of working with a laser scanner is divided into three main steps. First, the general work plan is conceived (Fig. 5A), and the scanning locations are selected on this plan. Then the fieldwork, i.e. collecting scanner and/or topographic data, is carried out (Fig. 5B) and (Fig. 5C). Finally, the scanner is placed at the defined locations, according to the plan, to prevent hidden areas or shadows in the point clouds (Fig. 5D), and data are then collected.

\subsection{Second step}

In this step, data from the previous step are analyzed and organized for feeding into the BIM environment. In particular, raw data from the different scans are merged, filtered and softened, and indexed to facilitate efficient handling. Moreover, the information obtained from the historical documents, images, construction methods and dimensional data are analyzed and organized. The entire set of data is compared against the technical and historical 
construction details of the different architectural periods, in order to complement the specific records of the processed point cloud. This feedback between the spatial and semantic data allows the complexity of the modeling process required by the HBIM library to be reduced.

\subsection{Third step}

Finally, the data can be imported and stored in the BIM environment, and the accurate and efficient modeling of the different architectural components can be addressed. The modeled components are then incorporated into the HBIM library and represent the 3D model of the building. Moreover, analyzed buildings or monuments often suffer from different pathologies or deformations derived from the passage of time or structural problems, such as sloping walls, cracks or missing items. Point clouds provide the actual shape and spaces of the buildings, which is important for achieving an accurate modeling of each component.

In order to address the accurate modeling of the architectural objects, the elements are first classified into regular and irregular surfaces. The classification criterion is given by the complexity of the shape, evaluated upon the amount and type of details. On the one hand, such elements as capitals, archivolts and ornaments, which have many details, will be assumed to be irregular or organic surfaces. On the other hand, such simple or uniform elements as columns, walls, windows and doors will be assumed to be regular surfaces

Thanks to the graphic information of the point clouds and the knowledge of the rules and constructive patterns of the architectural period the building belongs to, a design of multiple views, cuts and sections made on the point cloud is created. The information obtained from these actions will allow the actual monument to be modeled.

In our case, the analyzed building belongs to the Romanesque architectural period. First, the point cloud representing the monument is inscribed in a section box (Fig. 6A), i.e., a conceptual tool that delimits the 3D model used to carry out the different cuts. To be precise, the cuts are made on the point cloud in longitudinal and transversal directions, following the 
divisive concept of the current architectural period. These cuts will be the head, body and foot (Fig. 6B) of the monument, and will serve to show the composition and internal layout of the building, as well as to generate an estimate of the dimensions of the various elements and surfaces.

Subsequently, a set of grids is created on the planimetry (Fig. 7). These grids are finite surfaces seen as straight lines, arcs or multi-segments at a given level. These grids are responsible for marking the outline of the cloud surfaces. Moreover, each line serves as a reference to extract the current distances.

The resulting views of the point clouds, which the BIM platforms usually divide into North, South, East and West, will be used as a profile to delimit the use of levels at different model heights (Fig. 8A). These levels are finite horizontal planes that constitute a reference for determining the vertical distances between one point and another. Following the constructive logic of the abovementioned architectural period, and according to (Schueremans et al., 2007), the levels will be placed on the basis of the materials that were used, these materials being the masonry or ashlar stone that are styled, parallelepipedic blocks. The approximate size of the stones may range from 40 to $200 \mathrm{~cm}$ in length, 30 to $60 \mathrm{~cm}$ in height and 4.5 to 35 $\mathrm{cm}$ in thickness (Fig. 8B). Moreover, on each plane obtained through the use of the abovementioned levels, the grids previously created (or new ones) are used for marking the cloud.

Once the said actions have been completed, the section planes are traced out on the major plant provided by the point cloud (Fig. 9 A). The planes cross the center of the structural or supporting elements that compose the building (walls, pillars, columns, arches and vaults in the case of the constructive logic of a Romanesque monument). This strategy allows the deformations that affect the elements or the morphological profiles to be reflected more accurately and clearly (Fig. 9B). Then, vertical grids are traced on each section to perform the same function described previously. New levels at aditional heights can also be used, if 
necessary, to verify each component more accurately.

After completing this procedure, thanks to the levels, dimensions and grids, the point cloud will be represented by closed, sized polygons, thus allowing the cloud to be used as a guide for modeling the different architectural components.

When the geometry of a given surface is uniform and simple according to its appearance in view, section or elevation, the modeling will be performed using the basic tools of BIM environments. In addition, the parameters of the objects already in the BIM internal library, such as walls, windows, doors or columns (Fig. 2), will be modified and adjusted to best describe the current component of the building. Moreover, the modified objects can be readily put in place on the project following the grid lines, levels and cloud sections.

On the other hand, when the geometry of a surface is irregular or complex, the modeling mainly starts with the sketch of vertical and horizontal reference planes on a $2 \mathrm{D}$ work plane (Fig. 10A). These planes allow lines and geometries used to generate the profiles of the architectural component to be drawn. In order to accurately model each profile, the images representing the frames and proportions of the current element will be inserted, and the perimeter of the shape will be drawn on these images using the model lines (Fig. 10B).

Subsequently, now in a 3D work environment, the use of reference lines is the key to generating the 3D virtual model (Fig. 10C). These reference lines are actually useful for drawing the profile of any element. Reference points will be plotted on the reference lines, and it is these points which are responsible for linking the 2D profiles to the reference lines. Then, the tools for creating the solid geometry of each designed element are used. At the end of this action, the parameters concerning size, materials, textures, real images and historical data of each obtained element are created (Fig. 10D).

The elements modeled thanks to the designed methodology simulate the building in 3D. These elements are then incorporated into the design of an HBIM library and represent a 
solution for recurring $3 \mathrm{D}$ modeling of a wide range of buildings in the same style. This becomes possible due to the flexibility of the modeled elements that can change in shape and proportions, thus adapting to new requirements and projects without having to start from scratch.

Fuirthermore, the BIM platforms have the potential to create version types or levels-ofdevelopment (LOD) (Bedrick, 2008). These levels are references that allow the specification and articulation of the information required to represent a given element on its different design stages and the construction it is located in, linked to the possibility of modifying the element parameters and shape. Working with these levels is easy and flexible, as the content of each level is consistent with the project needs. Three levels of detail can be considered:

- LOD 100: The element model is a conceptual design and provides an overview of the volume, orientation and area.

- LOD 200: The element model is a schematic design and provides an overview with approximate information about size, shape, location and orientation. Non-graphical information can be attached to the models

- LOD 300: The element model provides a graphical representation of the information and precise geometry about size, shape, location and orientation. It can be used for construction documentation. The non-graphical information can be attached to models.

- LOD 400: The element model represents the same features provided by the previous level, but adds the accurate measurement details for manufacturing, installation, assembly or construction.

- LOD 500: The last level of development represents the built project. This information is used as documentation for the operation and maintenance of facilities.

These five levels provide a valid support to understand and interpret the characteristics of the different elements, going from general to detailed data. An example of the different levels of 
development of a Romanesque capital is given in (Fig. 11). Moreover, it is important to understand that the components of the HBIM library can be used for both handling a virtual model of the historic buildings, and illustrating the damage and declination of each architectural element.

\section{Results}

The proposed methodology has been applied in a real case and a parametric HBIM library of the modeled elements has been created. The selected building is the church of 'Santa Maria la Real de Mave', a monument of the Northern Spanish Romanesque period (Fig. 12A). This church is located within the monastery of Santa Maria, in the village of Santa Maria de Mave (Aguilar de Campoo, Palencia, Spain) (Fig. 12B).

The said building dates from the first half of the eleventh century (Wikipedia, 2015). Its current appearance is the combination of its constructive history and the reforms carried out in the sixteenth and seventeenth centuries (Arquivoltas, 2015; Arte guias, 2015; Romanico norte, 2015). The current neoclassic cloister was built during this last period. The church has a basilica plant, divided into three naves, with three articulated aisles topped by a triple head of semicircular apses. The flashlight tower is crowned with pendentives and a polygonal dome. The basilica plant and its distribution can be seen in (Fig. 13). Three pairs of cruciform pillars with semi-columns adjoining on every front, with the exception of the side arches, delimit the three longitudinal sections of the naves and arms of the transept. The central nave is covered by a barrel vault, and is separated into three sections by pointed arches.

Obtaining graphic information on the dimensions, proportions, shape and state of the church of 'Santa Maria la Real de Mave' can be an overwhelming process, due to the paucity of public data about this monument. To solve this problem, the workflow of the methodology proposed in the current paper has been followed, combining point clouds and historical sources. 
The church has been digitized using a Leica HDS 3000 "Time-of-flight" laser scanner and images have been taken using a Canon PowerShot G6 (7.1 megapixel) digital camera. A total of $313 \mathrm{D}$ scans have been taken inside and out, from an average distance of $20 \mathrm{~m}$, to a $4 \mathrm{~mm}$ standard deviation accuracy (Fig. 14). Over 14 million 3D points have been collected, along with 135 photographs.

The Autodesk Revit software has been used to model the building. This software is an efficient BIM platform suitable for accurately modeling both regular and irregular surfaces, and the geometric anomalies of the different elements. It also has the advantage of generating the construction documents with a high level of flexibility. It also provides all the necessary tools to implement the proposed methodology.

Revit works with the so-called families. A family is a set of elements of similar appearance, with common parameters and uses. Families with similar characteristics are included, in turn, in a higher level entity called "category." For each category, the object type and general properties will be defined. The families of each category can be classified according to their source in System, Place or Component Families. The virtual model of the church has been built using components of a particular family located in the program library.

The walls have been assumed to be regular surfaces, and have been modeled using the "Architecture" Revit tool. This tool allows a wall family to be created, one that already exists in the Revit internal library, to represent the requested surface. A number of modifications have been made to the different parameters (size, identity data, type of materials and finishes, graphics and analytical properties) in order to fit the current project. These elements have been built as "System Families". A representative example can be seen in (Fig. 2).

Vaults, domes and arches have been assumed to be irregular surfaces. These elements can be modeled quite straightforwardly in a 3D environment, thus they have been created as "In place Families". Each component has been parameterized by its height, size and material. In 
addition, these components are important parametric objects for church architecture, given that they are part of the main structural elements. The set of vaults and domes created in this work is shown in (Fig. 15A), and the set of arcs is shown in (Fig. 15B).

Moreover, reproducing the rich ornamentation of the Romanesque Architecture is hard work. Therefore, the ornaments of the main entrance and the cruciform columns have been considered irregular surfaces and have been modeled externally by creating "Component Families", thanks to the use of the aided procedure described in the previous section. These elements may be reused in future projects with a similar architecture.

The "Family Entrance" model has been created externally and is part of the "Generic Model" category of the virtual model. In addition, the "Family Entrance" contains several types, such as Archivolt, Capital Base, Main Base, Capital, Front Column, Capital Cornices, Entrance Wall and Window.

The archivolt that enhances the main front has been divided into several individual arches that are considered as sub-types of the Arc type. The construction sequence of an arc is detailed in (Fig. 16A). The reference planes have been sketched on a 2D work plane and then, the solid volume has been created in a 3D environment.

The capital has been modeled in three sections. The first section refers to the sub-type "capital base", which is modeled as a cylinder. The other two sections refer to the leaf subtypes that decorate the capital base. These components have been parameterized by the dimensions, constraints, materials and finishes of the capitals. The leaves have been modeled in $3 \mathrm{D}$, using the reference lines and several reference points, to give the curved shape to the different levels of the model, as can be seen in (Fig. 16B)

The whole main entrance modeled in the project, with all its components, can be seen in (Fig, 16C). Each component profile has been designed according to the size and shape extracted from the point cloud. 
Furthermore, the "Cruciform Column Family" has been modeled externally too, and is part of the "Generic Model" category. The object types within this family are classified into Column Base, Terraced Column Base, Capital Terraced Column, Column Center and Terraced Column. (Fig. 17A) shows one of the cruciform columns. The representation of the types and sub-types that conforms the modeled families is shown in (Fig. 17B). A longitudinal section of the church showing the cruciform columns can be seen in (Fig. 17C)

As for the Level of Development (LOD), the "Low, Medium and Fine" levels have been represented. Each of them is suitable for the designated use, as can be seen in (Fig. 11).

Once the components have been modeled, they could be used as comparison objects with information about their actual size, derived from the point cloud. In addition, these components could also be used to automatically produce technical documentation, such as floor plans, elevations, section cuts, details and perspectives. An example of a longitudinal cut carried out on the model is shown in (Fig. 18A), and an example of a cross-section can be seen in (Fig. 18B)

In conclusion, the church has been completely modeled, as can be seen in (Fig. 19), and each architectural component has been parameterized. The components of the "Family Entrance" may be adapted to other monuments belonging to the same period and architectural style, thanks to their flexibility. For this reason, this family has been incorporated into the HBIM library.

The library created in this work is available through the link www.eii.uva.es/\%7Eeduzal/Hbim. We hope that this material will be useful for researchers in cultural heritage and completed through future interventions.

\section{Conclusions and future lines}

In this paper, a reverse architecture methodology has been proposed, aimed at 
demonstrating the creation of an HBIM library and its benefits for simplifying the work of architects, engineers, builders and other professionals involved in architectural heritage.

The laser scanner is a suitable surveying instrument that allows a dense point cloud of the buildings to be acquired. The collected data, after proper digital processing, can be introduced into BIM systems regardless of whether these systems are primarily based on simplified parametric models more suited to modern architecture or industrial elements.

Ideally, BIM platforms would allow architectural components to be built automatically from point clouds. However, in practice, human intervention is required to a certain extent, in order to model the different elements. The proposed methodology systematizes the whole process, thus facilitating the heritage reverse architecture and helping preservation and refurbishment projects.

Moreover, it has been shown that semantic-aware 3D models can be created in the BIM platforms, containing the construction methods and materials of each object, thus providing access to the life-cycle management and simulation within various disciplines. For this reason, the HBIM library created in this work will serve as a tool for managing restoration and conservation processes, and can be reused in future projects.

Finally, the virtual models obtained in this way can be used to carry out structural, energetic, luminous and temporal analysis, as well as to interpret the different construction elements and the missing elements. This new way of working has an important social and cultural value, so its adoption will represent a step forward in heritage.

Future research would focus on the fully-automated generation of parametric models of the different elements within a point cloud. BIM systems, more specifically the Revit platform, continue to grow strongly year after year, and it is expected that future versions will improve the appearance and connection to other virtual platforms, thus expanding the digital world where researchers and public can interact concerning architectural heritage anytime, 
anywhere and with any device.

\section{Acknowledgments}

The authors acknowledge the ERASMUSMUNDUS (PEACE Program) for a scholarship to support Lopez Facundo José at the University of Valladolid, Spain, and "Heritage and Restoration" S.L.U. (Palencia, Spain) for its advice and support. This research project has received funding from the EU's H2020 Reflective framework program for research and innovation under grant agreement no. 665220.This work was also supported by the Ministry of Science and Innovation, fundamental research project ref. DPI2014-56500 and the Junta de Castilla y León ref. VA036U14.

\section{References}

Alsadik, B., Gerke, M., \& Vosselman, G. (2013). Automated camera network design for 3D modeling of cultural heritage objects. Journal of Cultural Heritage, 14(6), 515-526.

Azhar, S. (2011). Building information modeling (BIM): Trends, benefits, risks, and challenges for the AEC industry. Leadership and Management in Engineering, 11(3), 241252.

Baik, A., Alitany, A., Boehm, J., \& Robson, S. (2014). Jeddah Historical Building Information Modelling" JHBIM"-Object Library. ISPRS Annals of the Photogrammetry, Remote Sensing and Spatial Information Sciences, 2(5), 41.

Baik, A., Yaagoubi, R., \& Boehm, J. (2015). Integration of Jeddah Historical BIM and 3D GIS for Documentation and Restoration of Historical Monument. The International Archives of Photogrammetry, Remote Sensing and Spatial Information Sciences, 40(5), 29.

Barazzetti, L., Banfi, F., Brumana, R., Gusmeroli, G., Oreni, D., Previtali, M., ... \& Schiantarelli, G. (2015). BIM from laser clouds and finite element analysis: combining 
structural analysis and geometric complexity. The International Archives of Photogrammetry, Remote Sensing and Spatial Information Sciences, 40(5), 345.

Bedrick, J. (2008). Organizing the development of a building information model.The American Institute of Architects, 9.

Cheng, H. M., Yang, W. B., \& Yen, Y. N. (2015). BIM applied in historical building documentation and refurbishing. The International Archives of Photogrammetry, Remote Sensing and Spatial Information Sciences, 40(5), 85.

Conant, K. J. (2001). Arquitectura carolingia y románica, 800-1200. Ediciones Catedra.

Del Giudice, M., \& Osello, A. (2013). BIM for cultural heritage. International Archives of the Photogrammetry, Remote Sensing and Spatial Information Sciences, 40, 225-9.

Dore, C., \& Murphy, M. (2012). Integration of HBIM and 3D GIS for Digital Heritage Modelling.

Dore, C., Murphy, M., McCarthy, S., Brechin, F., Casidy, C., \& Dirix, E. (2015). Structural simulations and conservation analysis-Historic building information model (HBIM). The International Archives of Photogrammetry, Remote Sensing and Spatial Information Sciences, 40(5), 351.

Gómez-García-Bermejo, J., Zalama, E., \& Feliz, R. (2013). Automated registration of 3D scans using geometric features and normalized color data. Computer-Aided Civil and Infrastructure Engineering, 28(2), 98-111.

Ibáñez, A. J. P., Bernal, J. M. M., de Diego, M. J. C., \& Sánchez, F. J. A. (2015). Expert system for predicting buildings service life under ISO 31000 standard. Application in architectural heritage. Journal of Cultural Heritage.

Jackson, T. G. (1920). Byzantine and Romanesque architecture (Vol. 1). University Press, 
(205-257)

Kimball, F., \& Edgell, G. H. (1918). A history of architecture. New York: Harper \& Brothers Publishers, (1), 217-275.

Lerones, P. M., Llamas, J., Gómez-García-Bermejo, J., Zalama, E., \& Oli, J. C. (2014). Using 3D digital models for the virtual restoration of polychrome in interesting cultural sites. Journal of Cultural Heritage, 15(2), 196-198.

Logothetis, S., Delinasiou, A., \& Stylianidis, E. (2015). Building Information Modelling for Cultural Heritage: A review. ISPRS Annals of the Photogrammetry, Remote Sensing and Spatial Information Sciences, 2(5), 177.

Lorente, J. F. E., \& Francisco, J. (2007). La metrología y sus consecuencias en los edificios de la Alta Edad Media Española. III: El Primer Románico en España. Artigrama: Revista del Departamento de Historia del Arte de la Universidad de Zaragoza, (22), 423-472.

Memoria Histórica del Monasterio de Santa María de Mave. Románico Norte. http://www.romaniconorte.org/es/contenido/index.asp?iddoc=1082. [En línea] Acceso: 25/11/2015

Monasterio de Santa María de Mave.

Wikipedia. http://es.wikipedia.org/wiki/Monasterio_de_Santa Mar\%C3\%ADa de_Mav e [En línea] Acceso: 25/011/2015

MOYA, J. (2012). Vamos a ver románico.

Murphy, M., McGovern, E., \& Pavia, S. (2009). Historic building information modelling (HBIM). Structural Survey, 27(4), 311-327.

Murphy, M., McGovern, E., \& Pavia, S. (2011). Historic building information modelling-adding intelligence to laser and image based surveys. ISPRS-International Archives of the 
Photogrammetry, Remote Sensing and Spatial Information Sciences, 3816, 1-7.

Oreni, D., Brumana, R., Georgopoulos, A., \& Cuca, B. (2013). HBIM for conservation and management of built heritage: Towards a library of vaults and wooden bean floors. ISPRS Annals of Photogrammetry, Remote Sensing and Spatial Information Sciences, 5, W1.

Oreni, D., Brumana, R., Della Torre, S., Banfi, F., \& Previtali, M. (2014). Survey turned into HBIM: the restoration and the work involved concerning the Basilica di Collemaggio after the earthquake (L'Aquila). ISPRS Annals of the Photogrammetry, Remote Sensing and Spatial Information Sciences, 2(5), 267.

Piazza, M., \& Riggio, M. (2007). Typological and structural authenticity in reconstruction: The timber roofs of Church of the Pieve in Cavalese, Italy.International Journal of Architectural Heritage, 1(1), 60-81.

Quattrini, R., \& Baleani, E. (2015). Theoretical background and historical analysis for 3D reconstruction model. Villa Thiene at Cicogna. Journal of Cultural Heritage, 16(1), 119-125.

Quattrini, R., Malinverni, E. S., Clini, P., Nespeca, R., \& Orlietti, E. (2015). From TLS to HBIM. High quality semantically-aware 3D modeling of complex architecture. The International Archives of Photogrammetry, Remote Sensing and Spatial Information Sciences, 40(5), 367.

$\begin{array}{llll}\text { Santa } & \text { María } & \text { de } & \text { Mave. }\end{array}$

guías. http://www.arteguias.com/monasterio/santamariamave.htm [En línea] Acceso: $25 / 11 / 2015$

Santa María de Mave. Arquivoltas. http://www.arquivoltas.com/8-palencia/02Mave01.htm [En línea] Acceso: 25/11/2015

Schueremans, L., Van Balen, K., Brosens, K., Van Gemert, D., \& Smars, P. (2007). Church 
of Saint-James at Leuven: Structural assessment and consolidation measures. International Journal of Architectural Heritage, 1(1), 82-107.

Serrano, F. L. (2001). La arquitectura románica en la provincia de Guadalajara(Vol. 5). AACHE Ediciones de Guadalajara.

Toldo, I., \& Carrara, G. BIM AND KNOWLEDGE MANAGEMENT FOR BUILDING HERITAGE.

Tomaževič, M., \& Lutman, M. (2007). Heritage masonry buildings in urban settlements and the requirements of Eurocodes: Experience of Slovenia.International Journal of Architectural Heritage, 1(1), 108-130.

Vecco, M. (2010). A definition of cultural heritage: From the tangible to the intangible. Journal of Cultural Heritage, 11(3), 321-324.

\section{Figure captions}

Figure 1: A) Georeferenced point could, (X, Y, Z). B) Georeferenced point could [(X, Y, Z) ; $(R, G, B)]$. Source: Own figures.

Figure 2: Parametric modeling of a wall associated with the different elements of objects: the properties can be modified when making changes in the numerical values in the table. Source: Own figures

Figure 3: Block diagram of the proposed methodology for building 3D virtual models and the subsequent HBIM library. Source: Own figures. 6

Figure 4: A) Figurative plant about modules and proportions. B) Section about a system of repetitive modules. C) Prototype of a richly decorated arch, typical of the Romanesque entrances. Source: A) adapted from Lorente \& Francisco, 2007; B) adapted from Kimball \& 
Edgell, 1918; C) adapted from Jackson, 1920.

Figure 5: A) General scanning work plan. B) and C) Scanner positioning. D) Simulation of hidden areas. Source: Own figures. 8

Figure 6: A) Longitudinal section of the point cloud. The section box is highlighted with a red dashed line. B) Church Foot. Source: Own figures.

Figure 7: Set of grids created on the planimetry. Source: Own figures.

Figure 8: A) East view of the point cloud with ashlar levels. B) Approximate stone size Source: Own figures. 10

Figure 9: A) section planes are traced out on the major plant provided by the point cloud. B) Longitudinal section with the inclinations of the walls marked in red. Inclination is less than $1 \%$ in all cases, therefore there is no danger of collapse. Source: Own figures. 10

Figure 10: A) Vertical and horizontal reference planes. B) Profile drawn upon the point clouds and the images of the element. C) Perimeter diagram and generation of the 3D solid element. D) Object parameters. Source: Own figures. 11

Figure 11: Example of the different levels of development. Source: own figures. 13

Figure 12: A) South facade of the 'Santa María la Real de Mave' Romanesque church. B) Location of the monument. Source: A) adapted from http://www.flickriver.com/photos/rabiespierre/tags/klaster/. ¡Error! Referencia de hipervínculo no válida.B) adapted from http://www.bing.com/maps/...... .13

Figure 13: Basilica plant divided into three naves. The main entrance and the bell tower are developed on the foot. The section of the three articulated naves and the flashlight-tower are 
developed on the body. Finally, a triple semicircular apse is found on the headboard. Source: Own figures.

Figure 14: Figure 14: Scanning process: external and internal data collection. Source: adapted from (Lerones et al., 2014)

Figure 15: A) Set of vaults and domes created. B) Set of arcs. Source: own figures. .15

Figure 16: A) Construction sequence of an uneven surface: creation of one of the arches that crowns the main entrance. B) Construction sequence of one of the leaves that decorate the capital and the obtained result. C) Final result of the "Family Entrance" modeling. Source: own figures. .15

Figure 17: A) Cruciform column. B) Types and sub-types that make up the modeled families. C) Longitudinal section, where the cruciform pillars with semi-columns and barrel vaults separated by arches cover the central nave. Source: own figures. 16

Figure 18: A) Longitudinal section of the church. B) Cross section of the church. Some dimensions are shown in both sections. Source: own figures. 16

Figure 19: Final result: the complete church. Source: Own figures. 16 


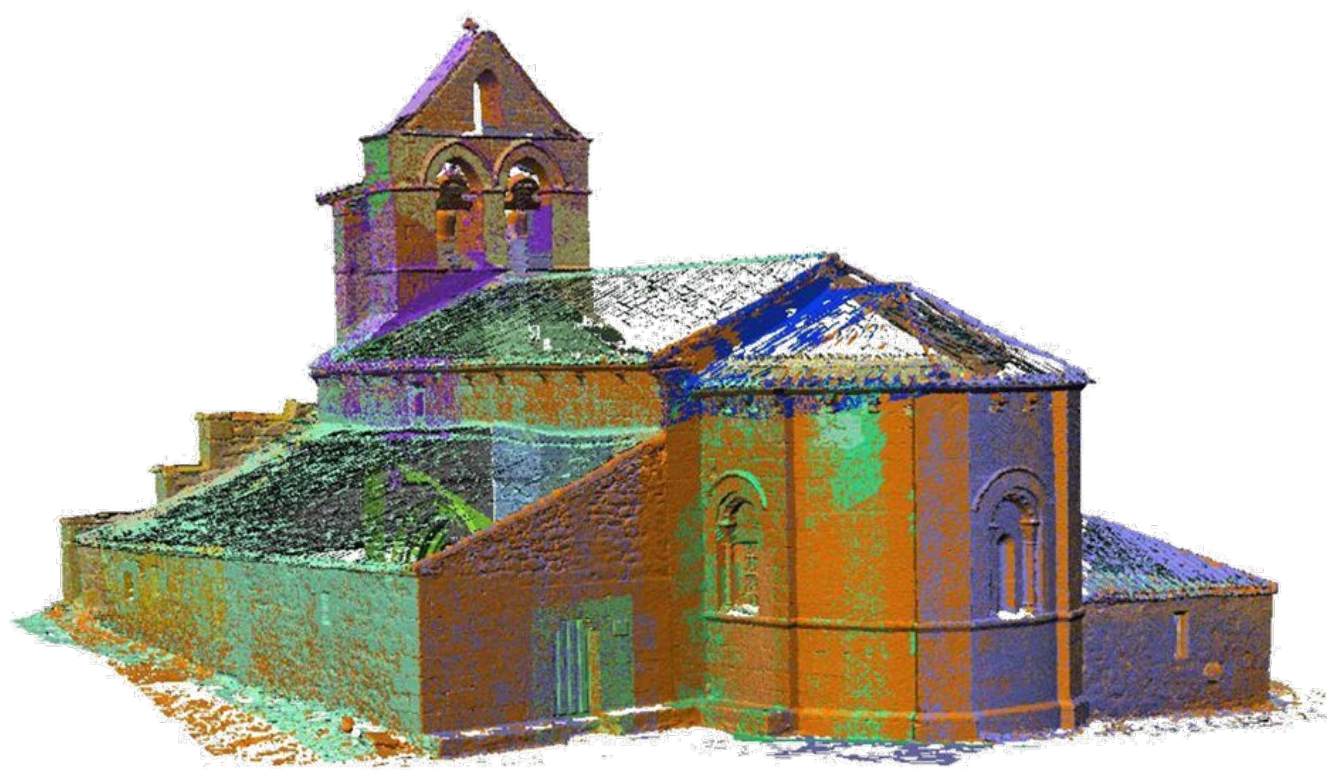

(A)

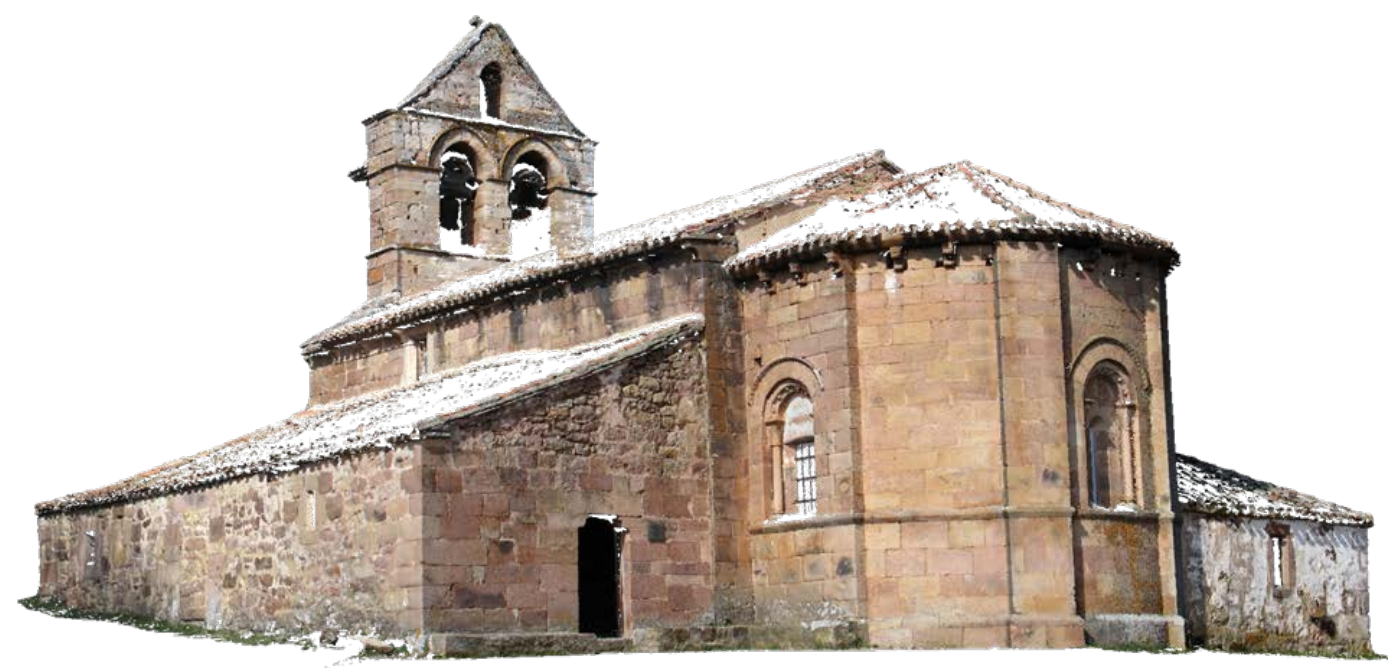

(B)

Figure 1: A) Georeferenced point could, (X, Y, Z). B) Georeferenced point could $[(\mathrm{X}, \mathrm{Y}, \mathrm{Z}) ;(\mathrm{R}, \mathrm{G}, \mathrm{B})]$.

Source: Own figures. 


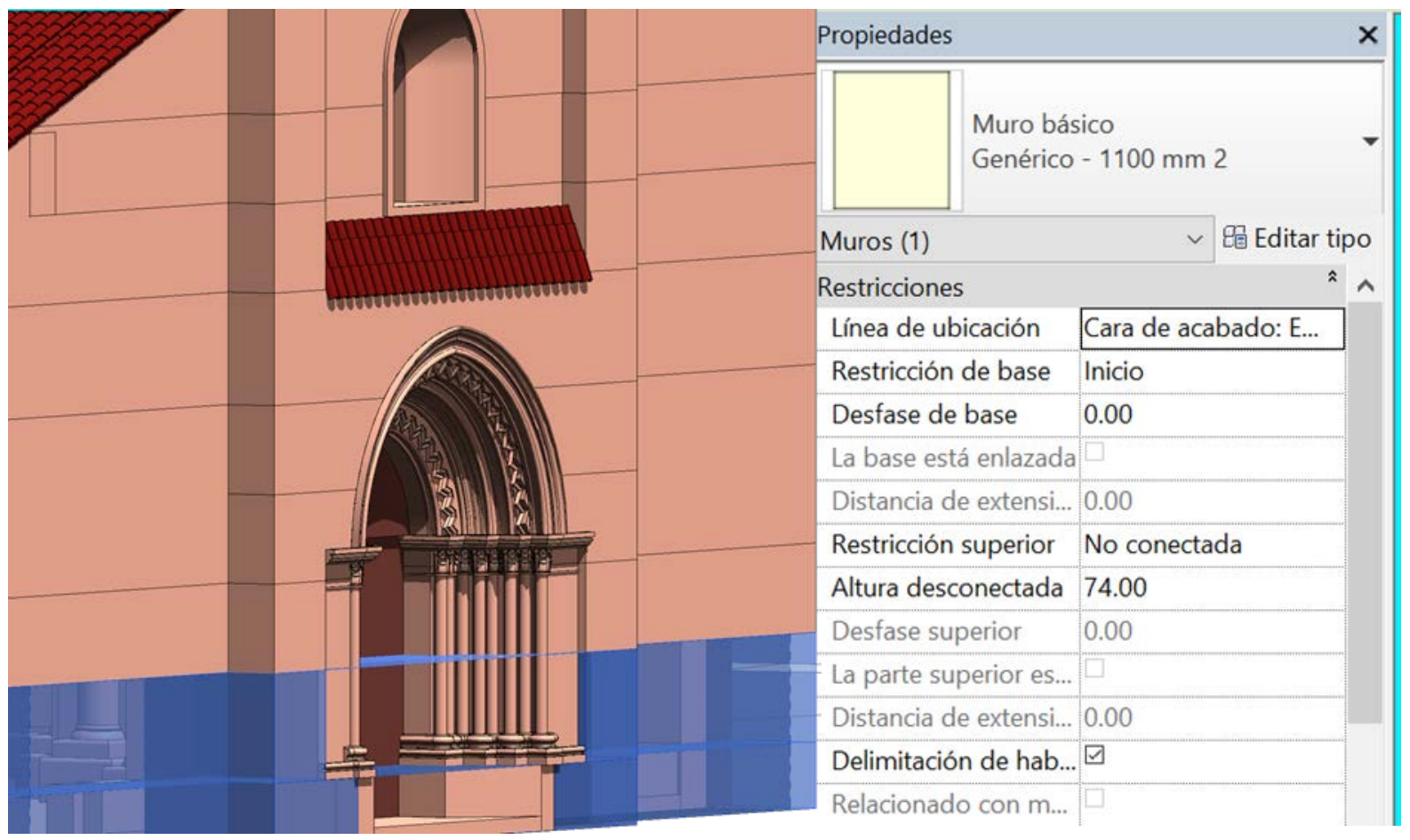

\section{Entrance Wall}

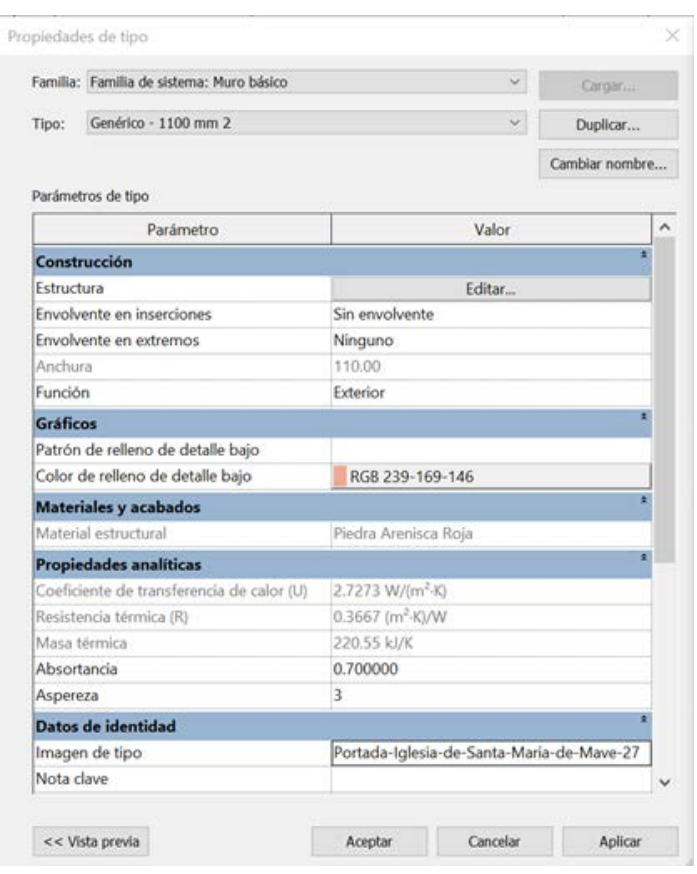

Parameters

\section{Properties}

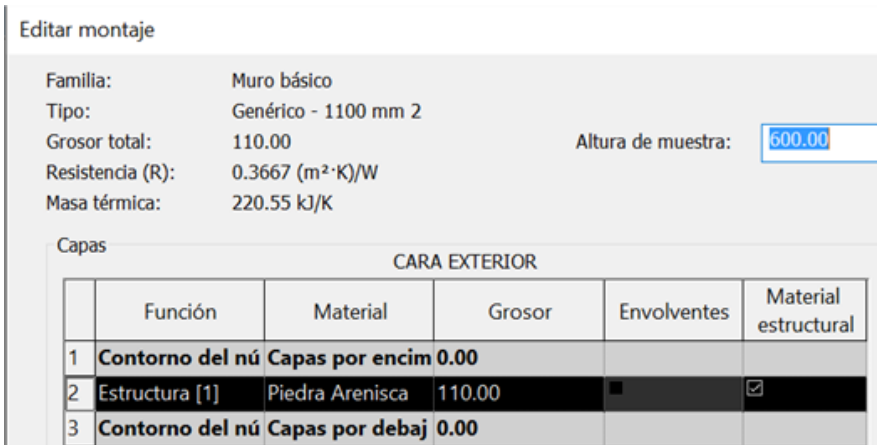

\section{Materiality specifications}

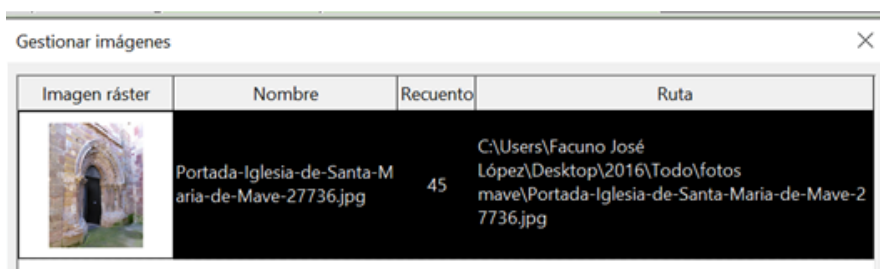

Semantic information

Figure 2: Parametric model of a wall associated to the different elements of objects: the properties can be modified when making changes in the numerical values in the table.

Source: Own figures. 


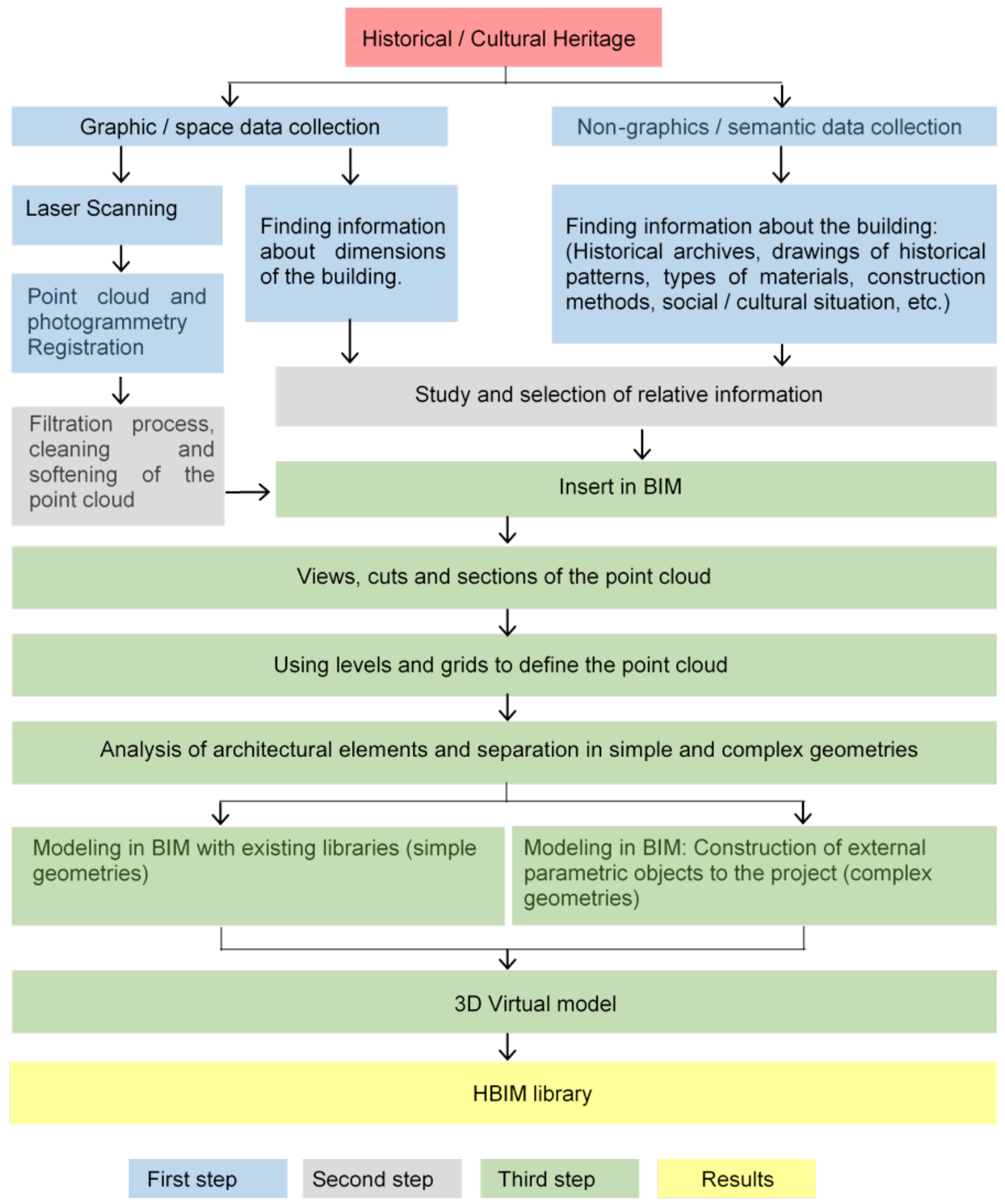

Figure 3: Block diagram of the proposed methodology for building 3D virtual models and the subsequent HBIM library.

Source: Own figures. 

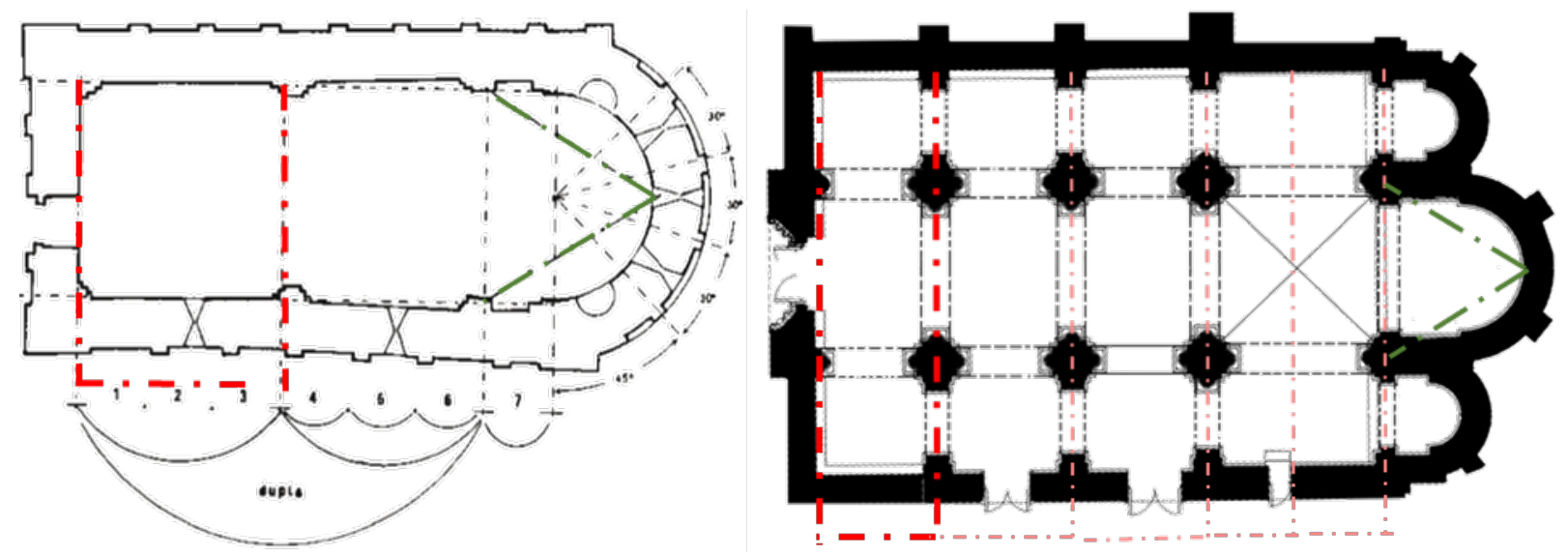

A)
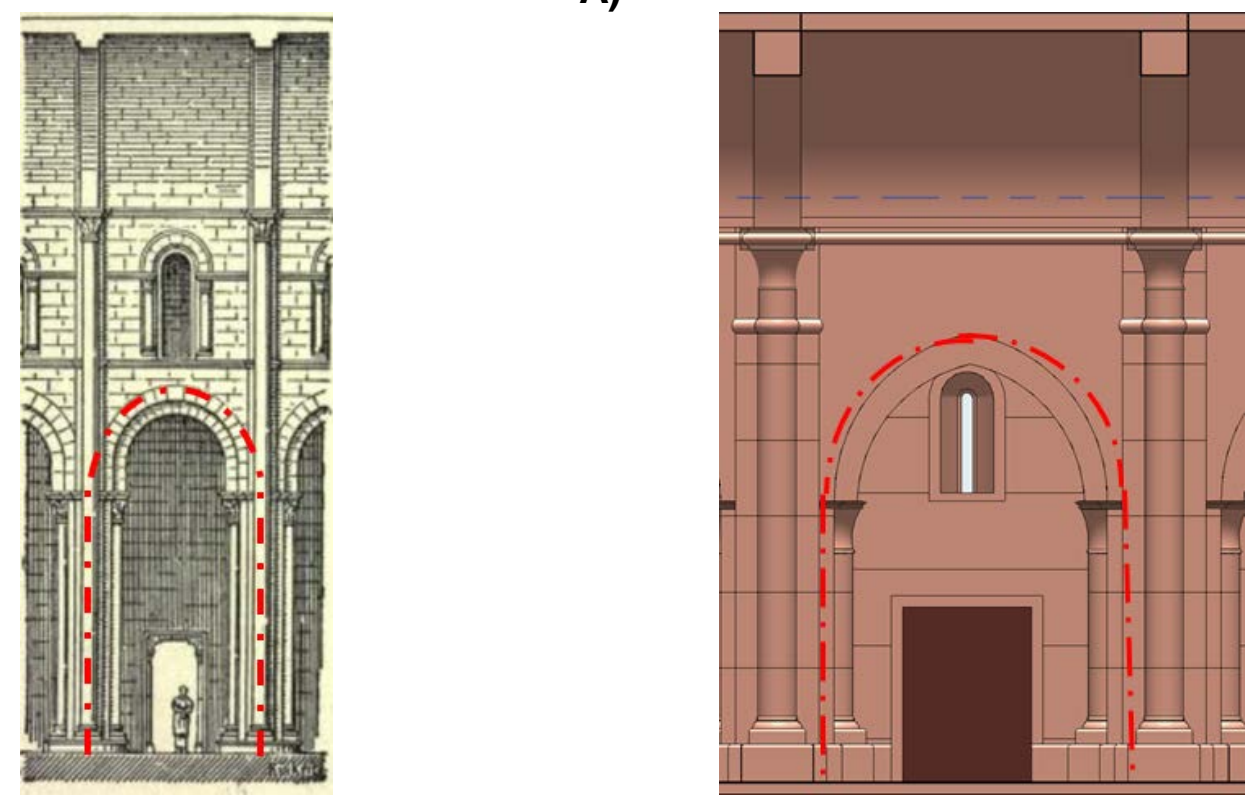

B)
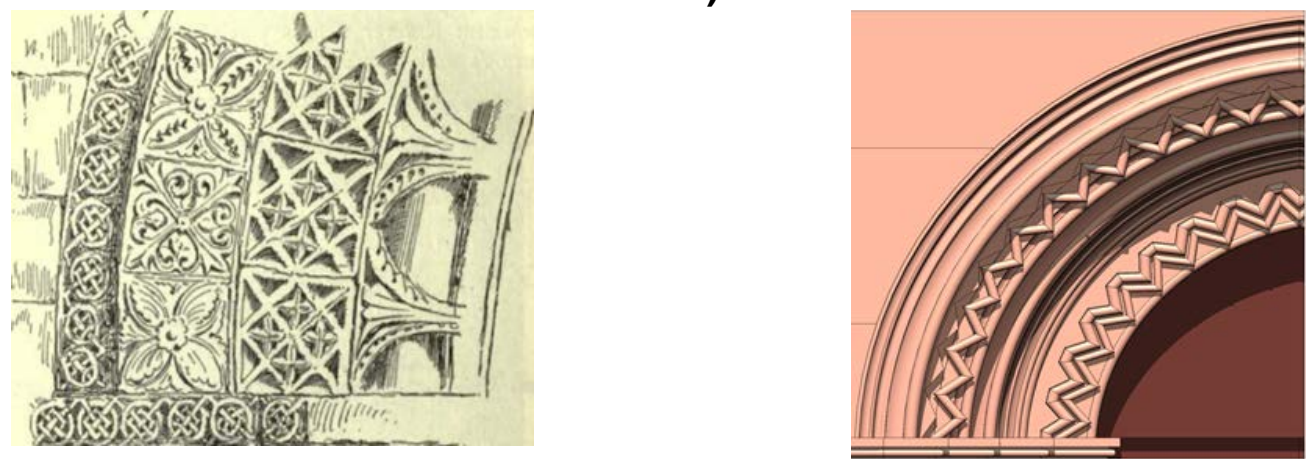

C)

Figure 4: A) Figurative plant about modules and proportions. B) Section about a system of repetitive modules. C) Prototype of a richly decorated arch, typical of the Romanesque entrances.

Source: A) adapted from Lorente \& Francisco, 2007; B) adapted from Kimball \& Edgell, 1918; C) adapted from Jackson, 1920. 


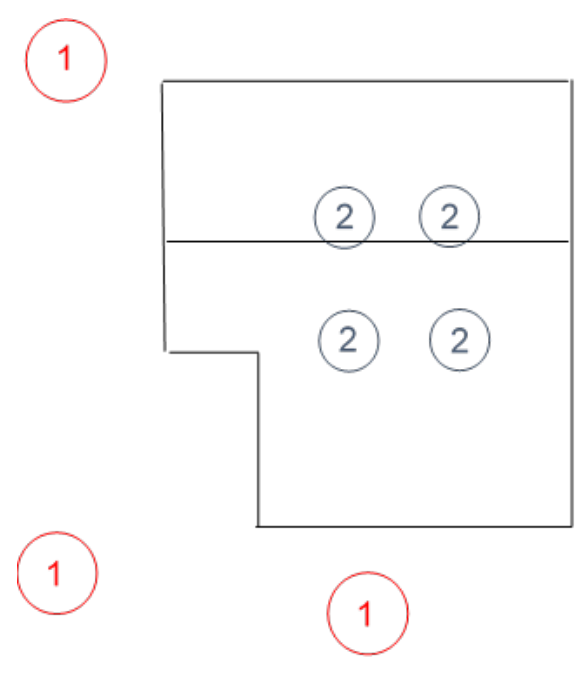

A)

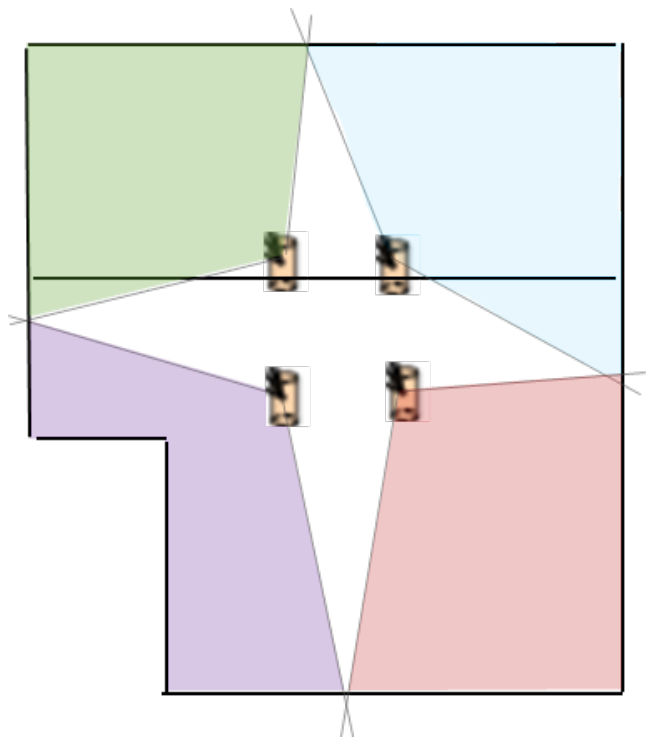

C)

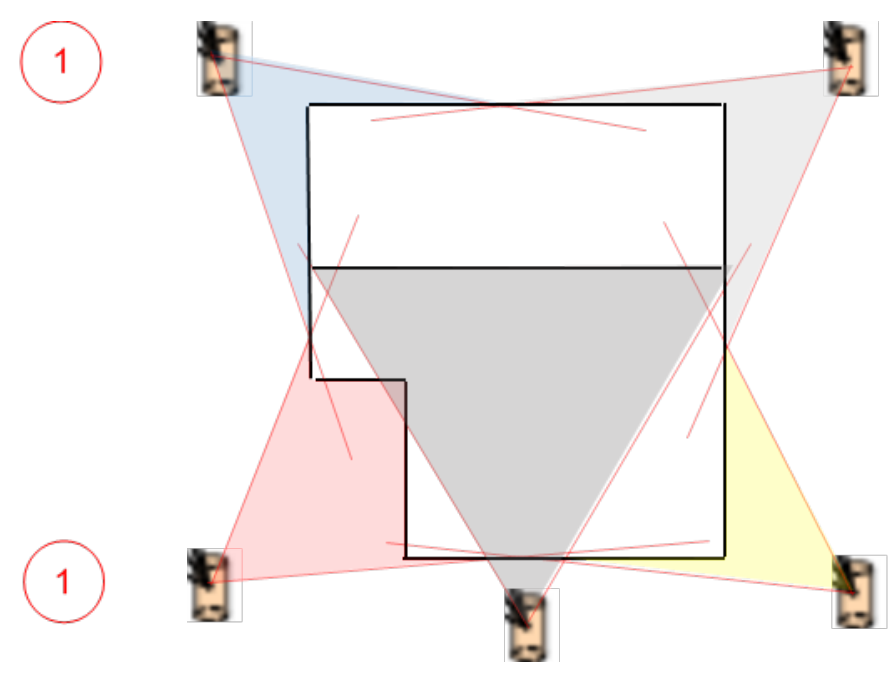

B)

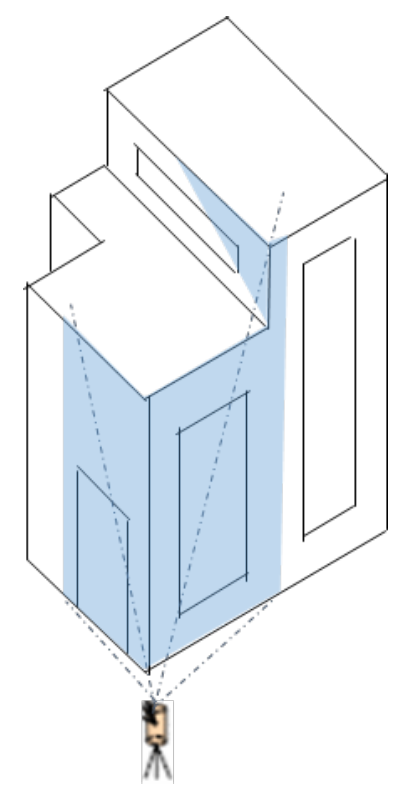

D)

Figure 5: A) General scanning work plan. B) and C) Scanner positioning. D) Simulation of hidden areas.

Source: Own figures. 


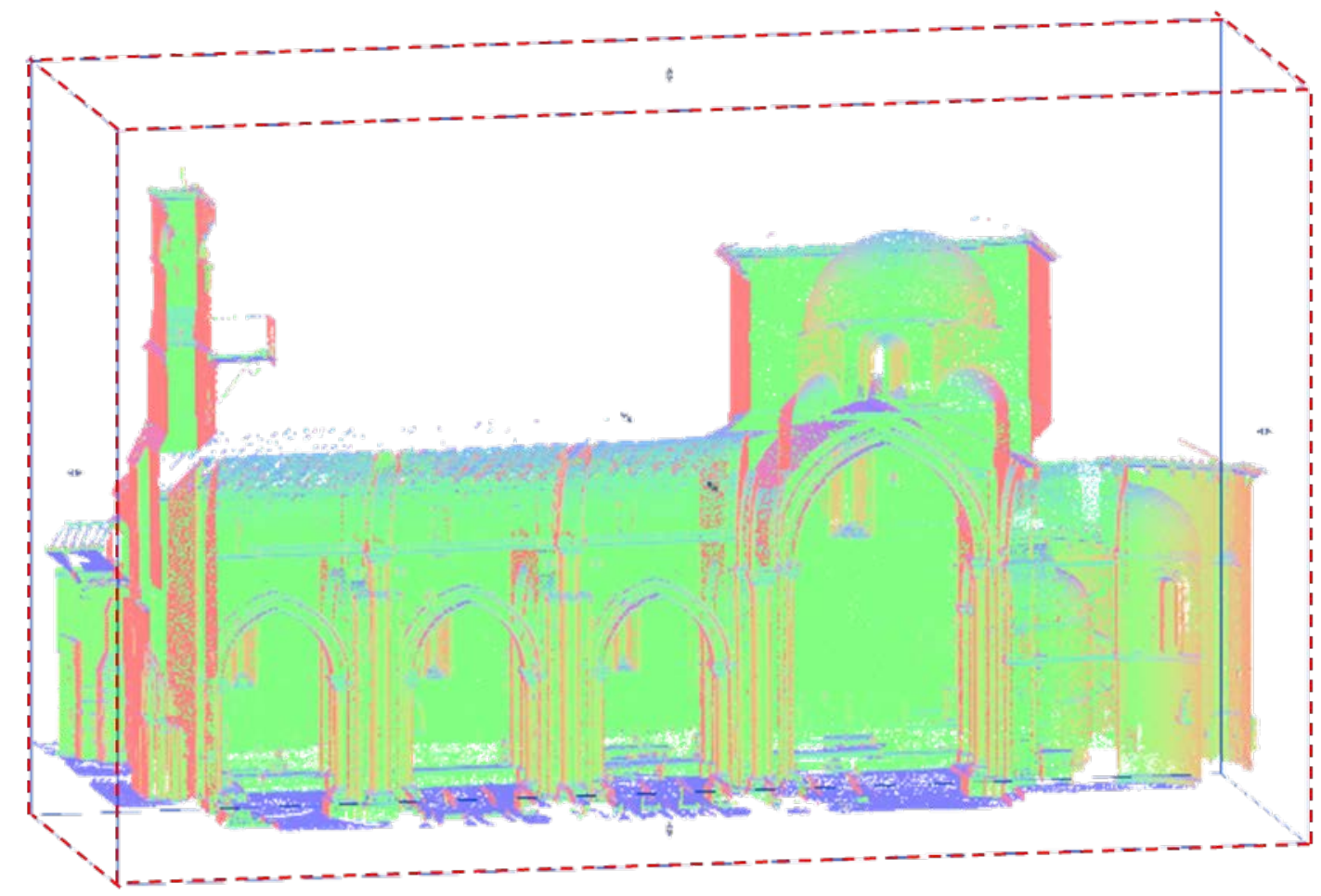

A)

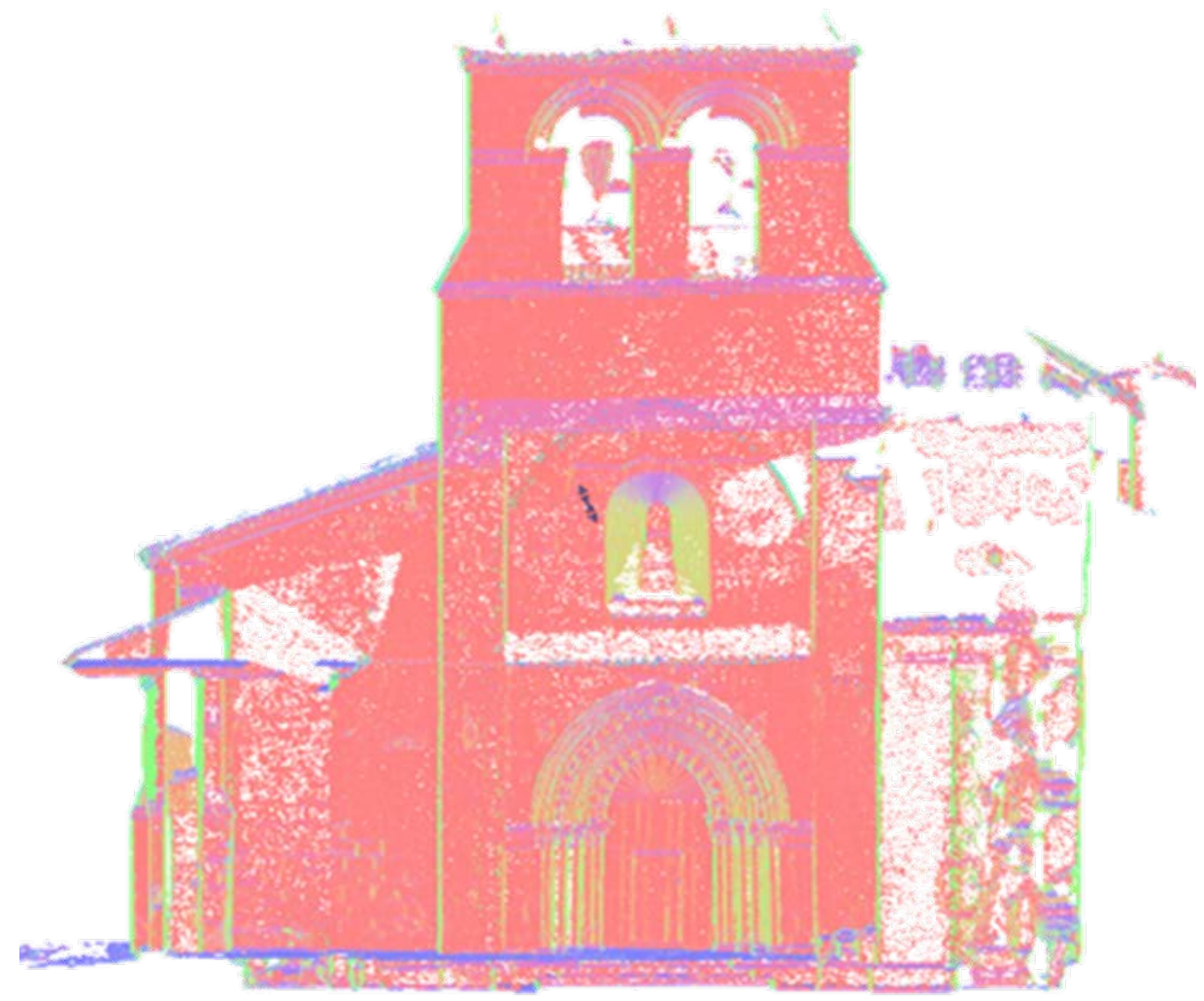

B)

Figure 6: A) Longitudinal section of the point cloud. The section box is highlighted with a red dashed line. B) Church Foot.

Source: Own figures. 


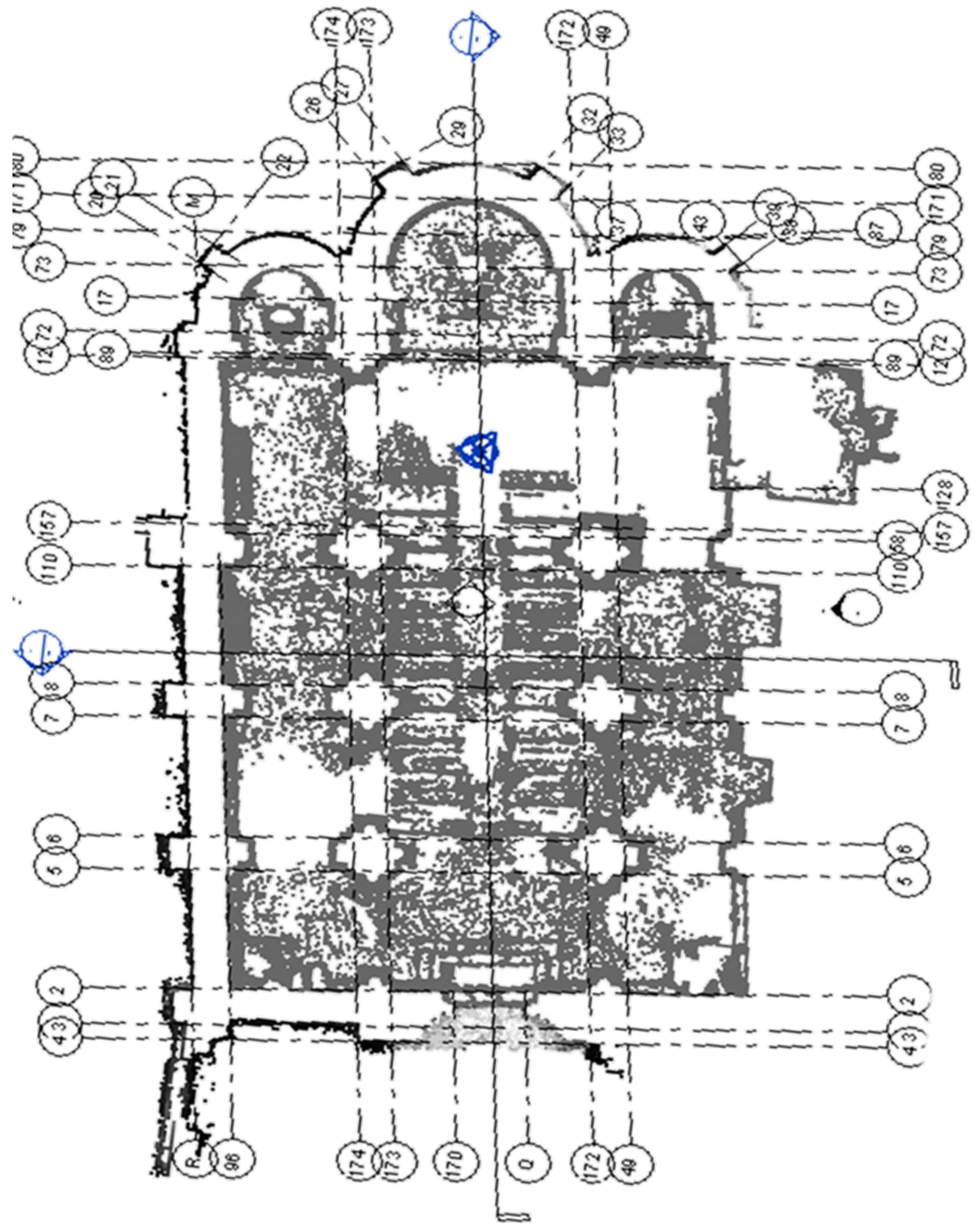

Figure 7: Set of grids created on the planimetry.

Source: Own figures. 


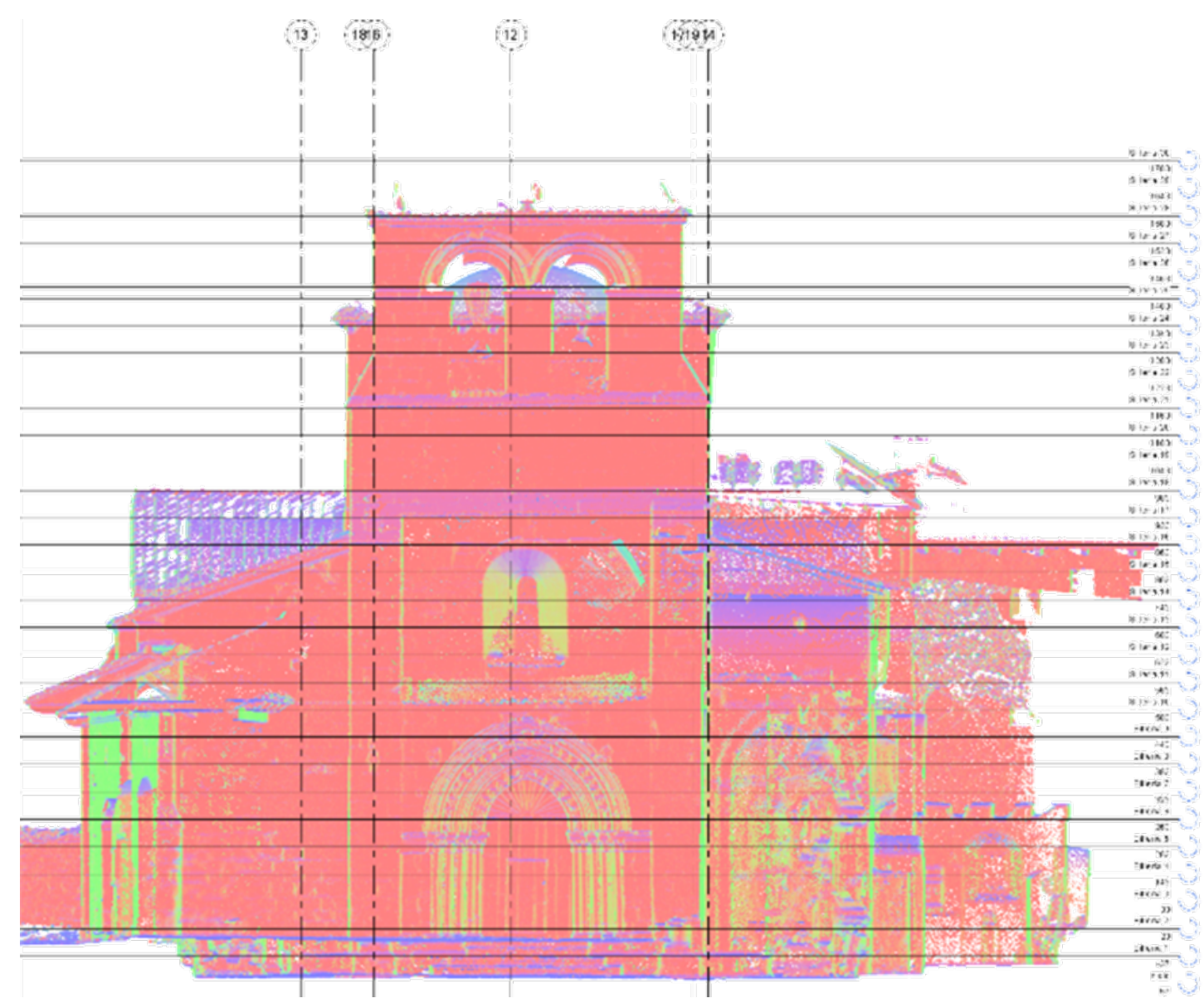

A)

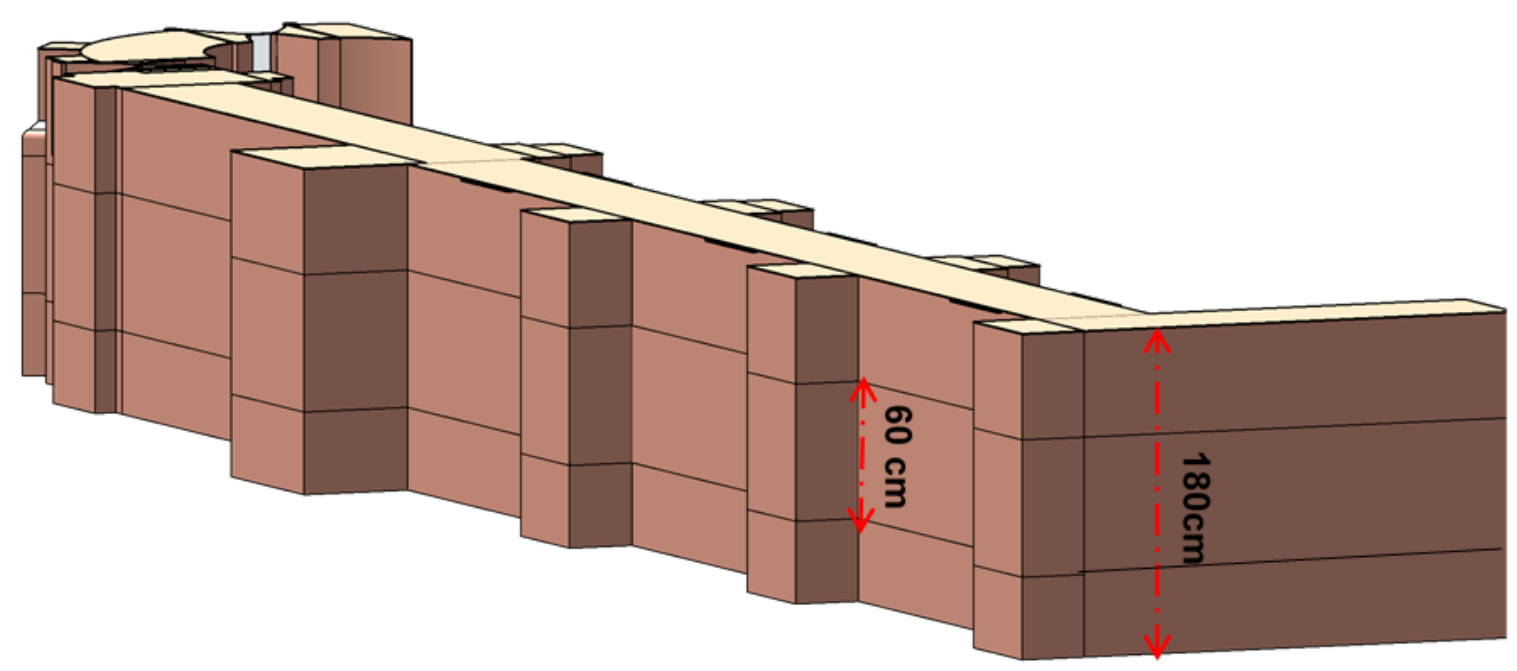

B)

Figure 8: East view of the point cloud with ashlar levels. B) Approximate stone size.

Source: Own figures. 


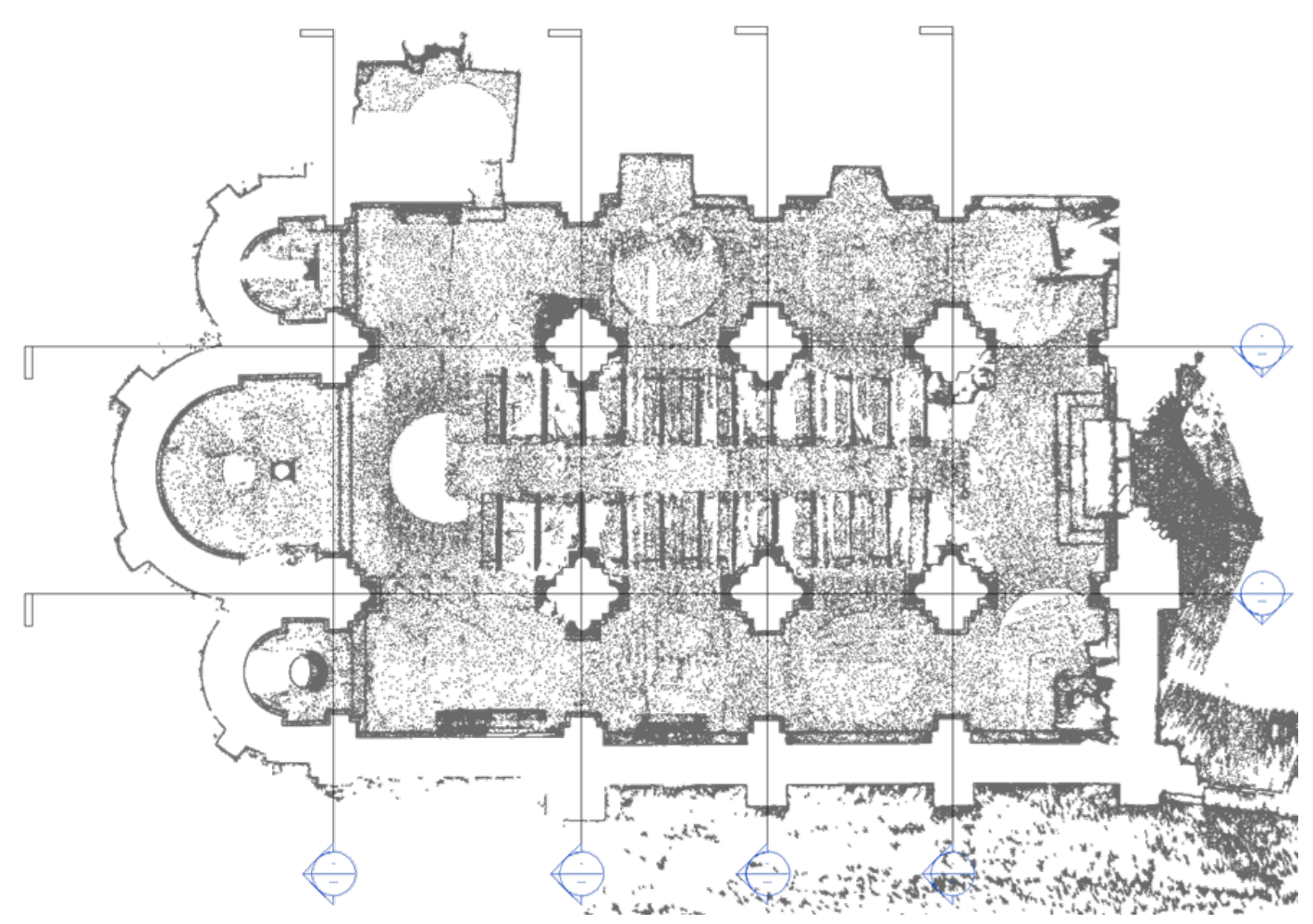

A)

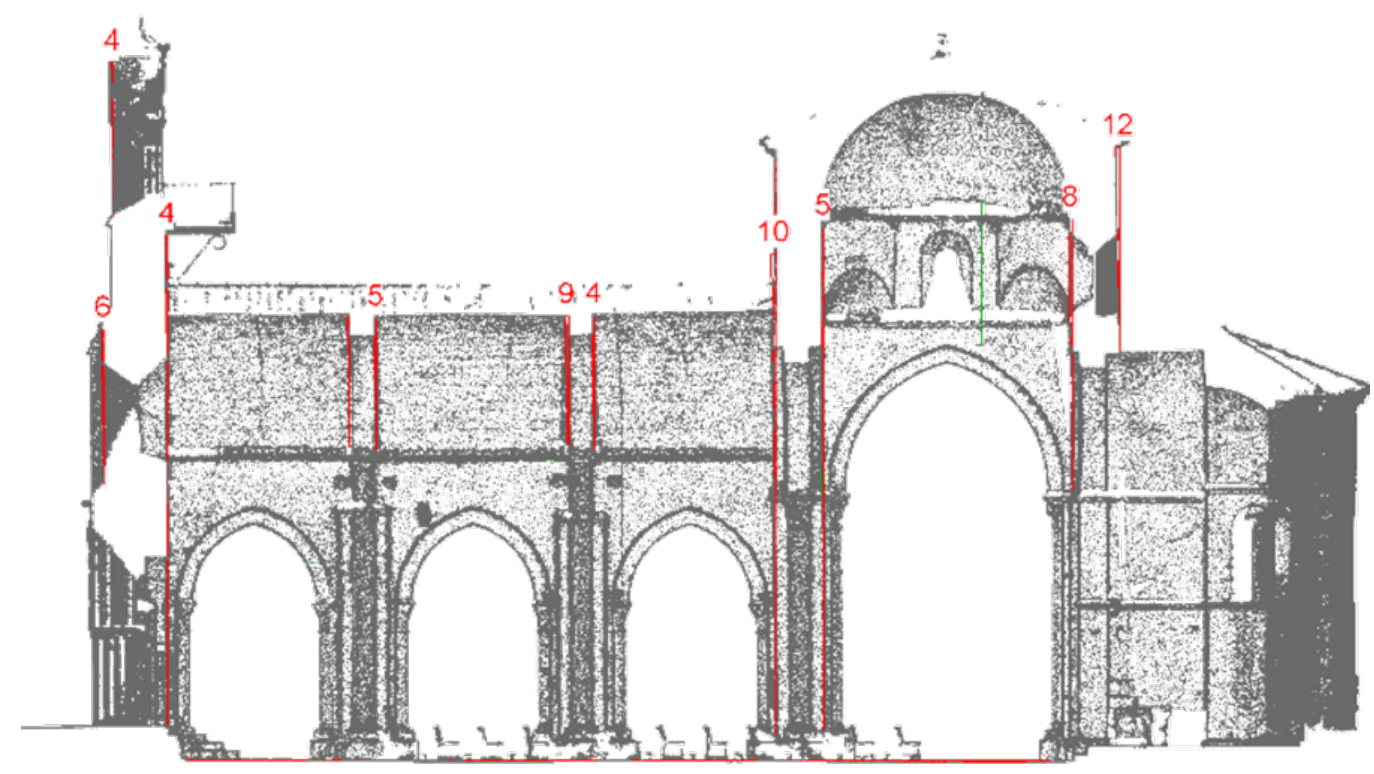

B)

Figure 9: A) section planes are traced out on the major plant provided by the point cloud. B) Longitudinal section with the inclinations of the walls marked in red. Inclination is less than $1 \%$ in all cases therefore there is no danger of collapse. Source: Own figures. 


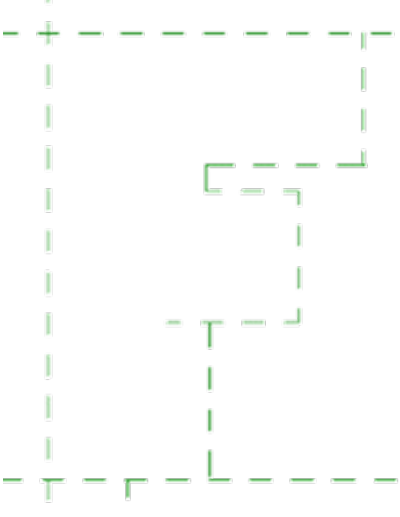

A)

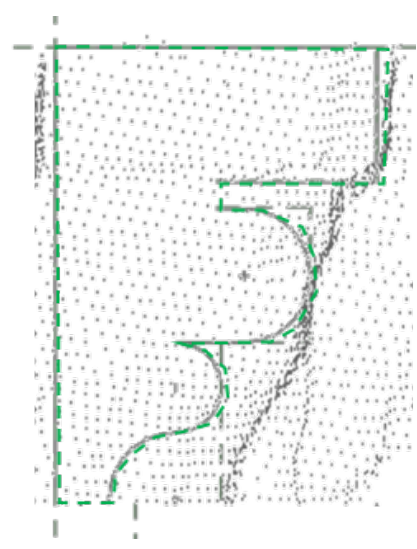

B)

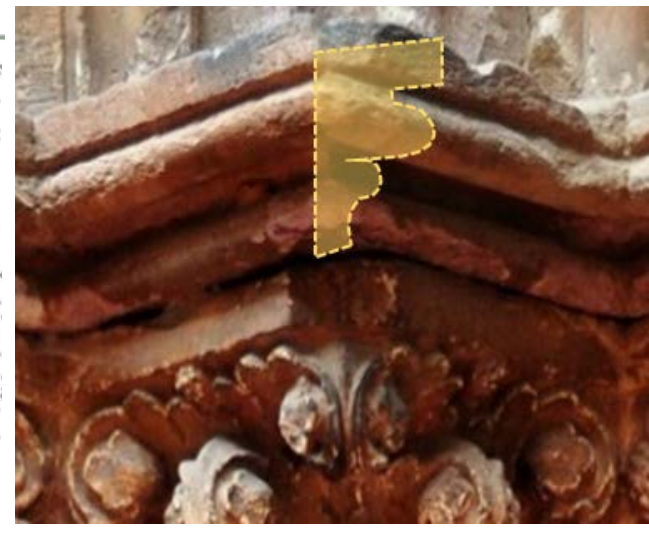

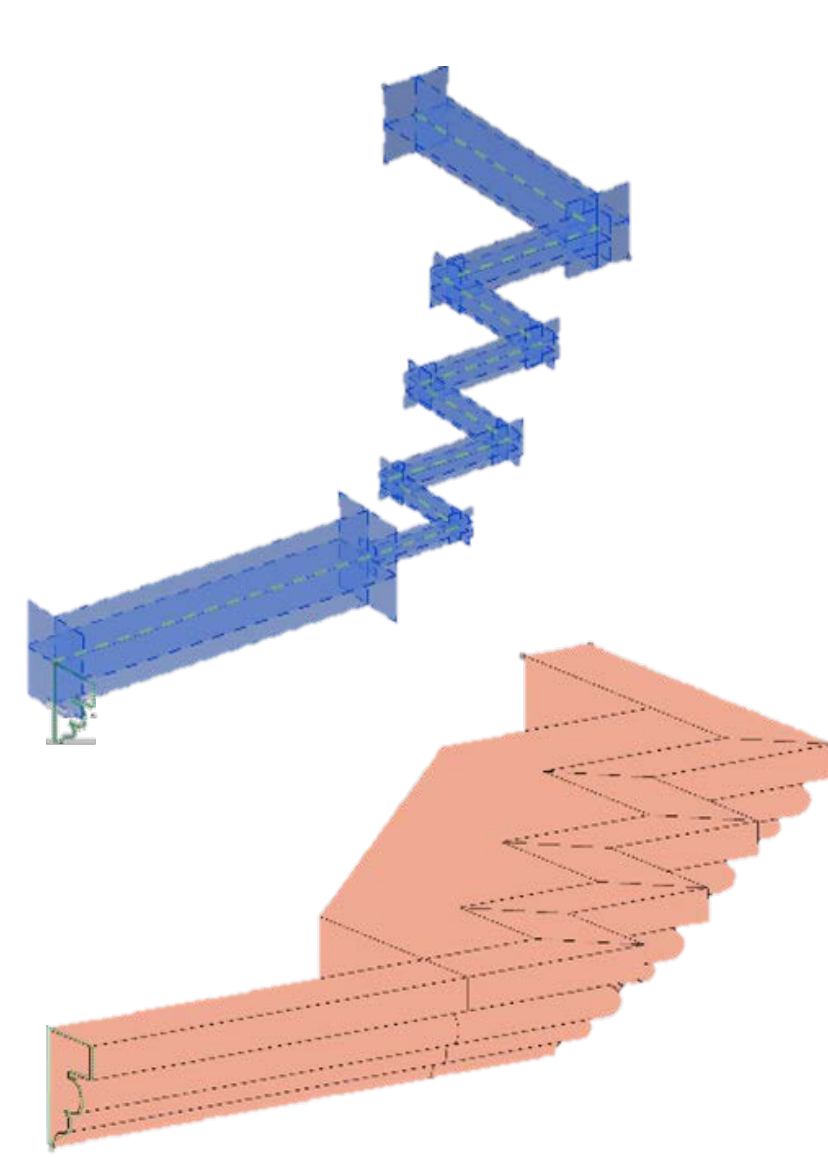

C)

Parámetros de tipo
\begin{tabular}{|l|l|}
\hline \multicolumn{1}{|c|}{ Parámetro } & \\
\hline Construcción & \\
\hline Estructura & Valor \\
\hline Envolvente en inserciones & Sin envolvente \\
\hline Envolvente en extremos & Ninguno \\
\hline Anchura & 110.00 \\
\hline Función & Exterior \\
\hline Gráficos & \\
\hline Patrón de relleno de detalle bajo & \\
\hline Color de relleno de detalle bajo & RGB $239-169-146$ \\
\hline Materiales y acabados & \\
\hline Material estructural & Piedra Arenisca Roja \\
\hline Propiedades analíticas & \\
\hline Coeficiente de transferencia de calo & $2.7273 \mathrm{~W} /\left(\mathrm{m}^{2} \cdot \mathrm{K}\right)$ \\
\hline Resistencia térmica (R) & $0.3667\left(\mathrm{~m}^{2} \cdot \mathrm{K}\right) / \mathrm{W}$ \\
\hline Masa térmica & $220.55 \mathrm{~kJ} / \mathrm{K}$ \\
\hline Absortancia & 0.700000 \\
\hline Aspereza & 3 \\
\hline Datos de identidad & \\
\hline Imagen de tipo & \\
\hline Nota clave & \\
\hline Modelo & \\
\hline Fabricante & \\
\hline Comentarios de tipo & \\
\hline URL & \\
\hline Descripción & \\
\hline
\end{tabular}

D)

Figure 10: A) Vertical and horizontal reference planes. B) Profile drawn upon the point clouds and the images of the element. C) Perimeter diagram and generation of the 3D solid element. D) Object parameters.

Source: Own figures. 


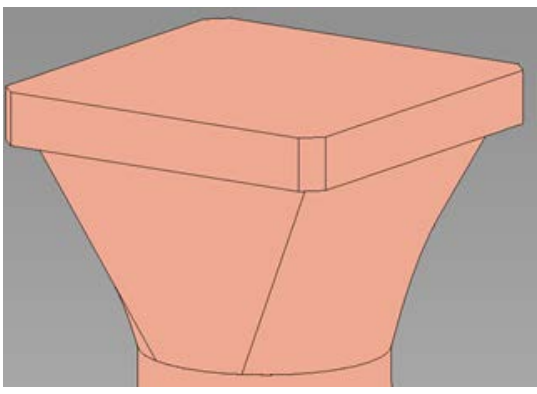

"Low" level

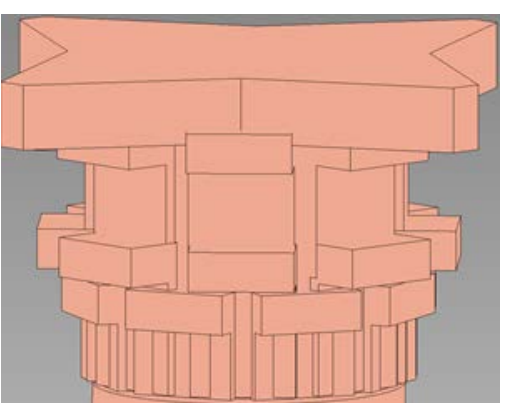

"Medium" level

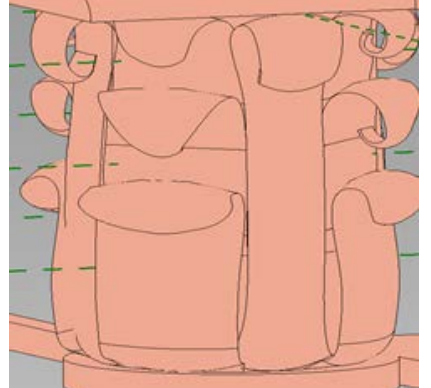

"Fine" level

Figure 11: Example of the different levels of development.

Source: Own figures. 


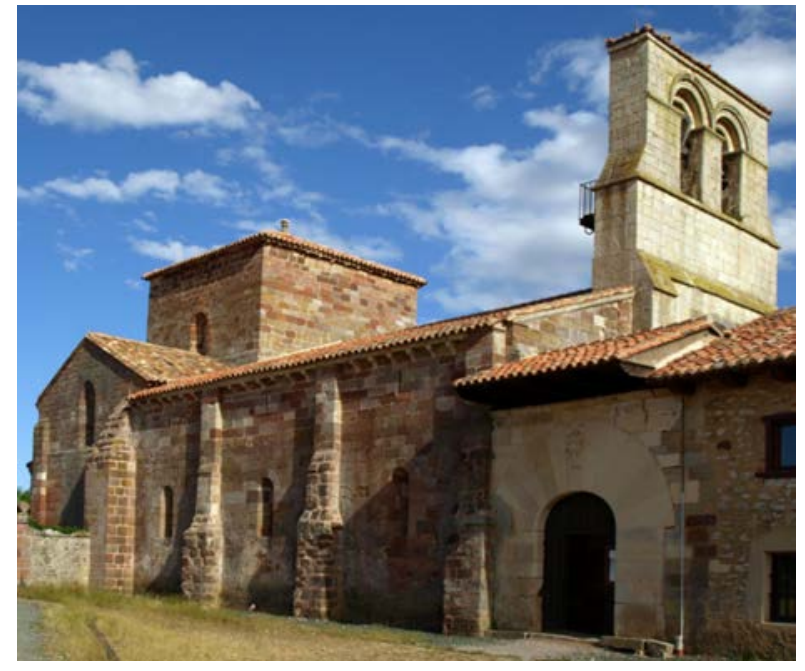

A)

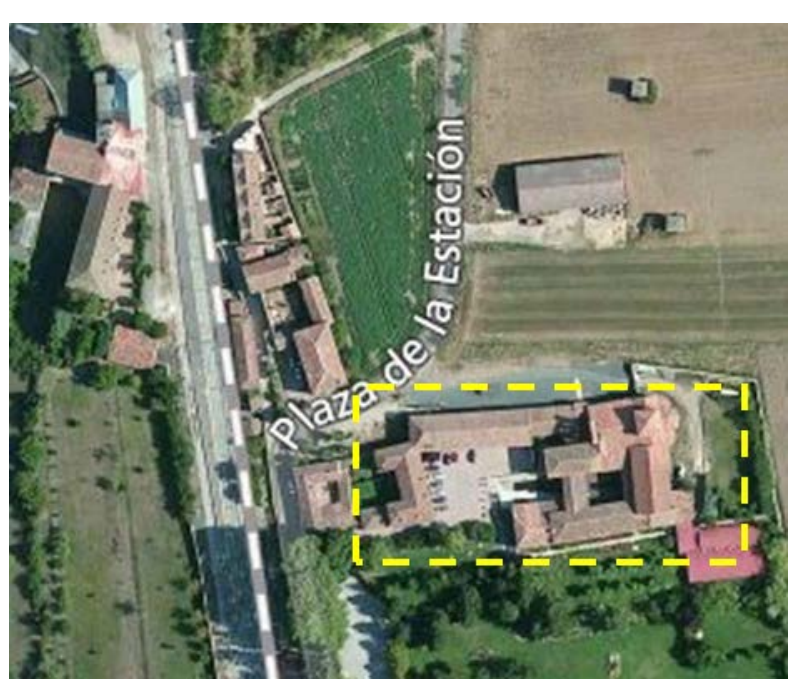

B)

Figure 12: A) South facade of the Santa María la Real de Mave Romanesque church. B) Location of the monument.

Source: A) adapted from http://www.flickriver.com/photos/rabiespierre/tags/klaster/. B) adapted from http://www.bing.com/maps/. 


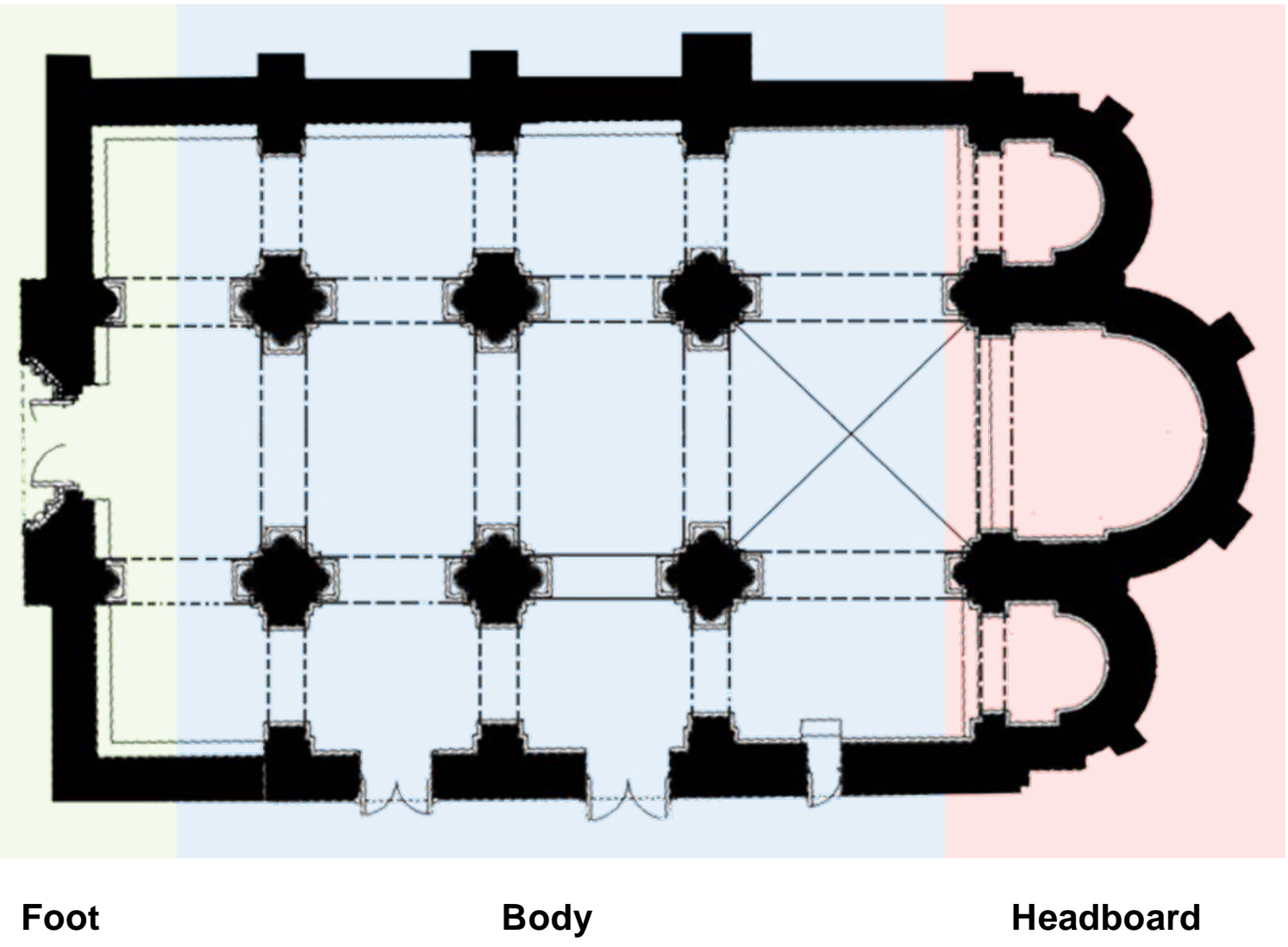

Figure 13: Basilical plant divided into three naves. The main entrance and the bell tower are developed on the foot. The section of the three articulated naves and the flashlight-tower are developed on the body. Finally, a triple semicircular apse is found on the headboard.

Source: Own figures. 

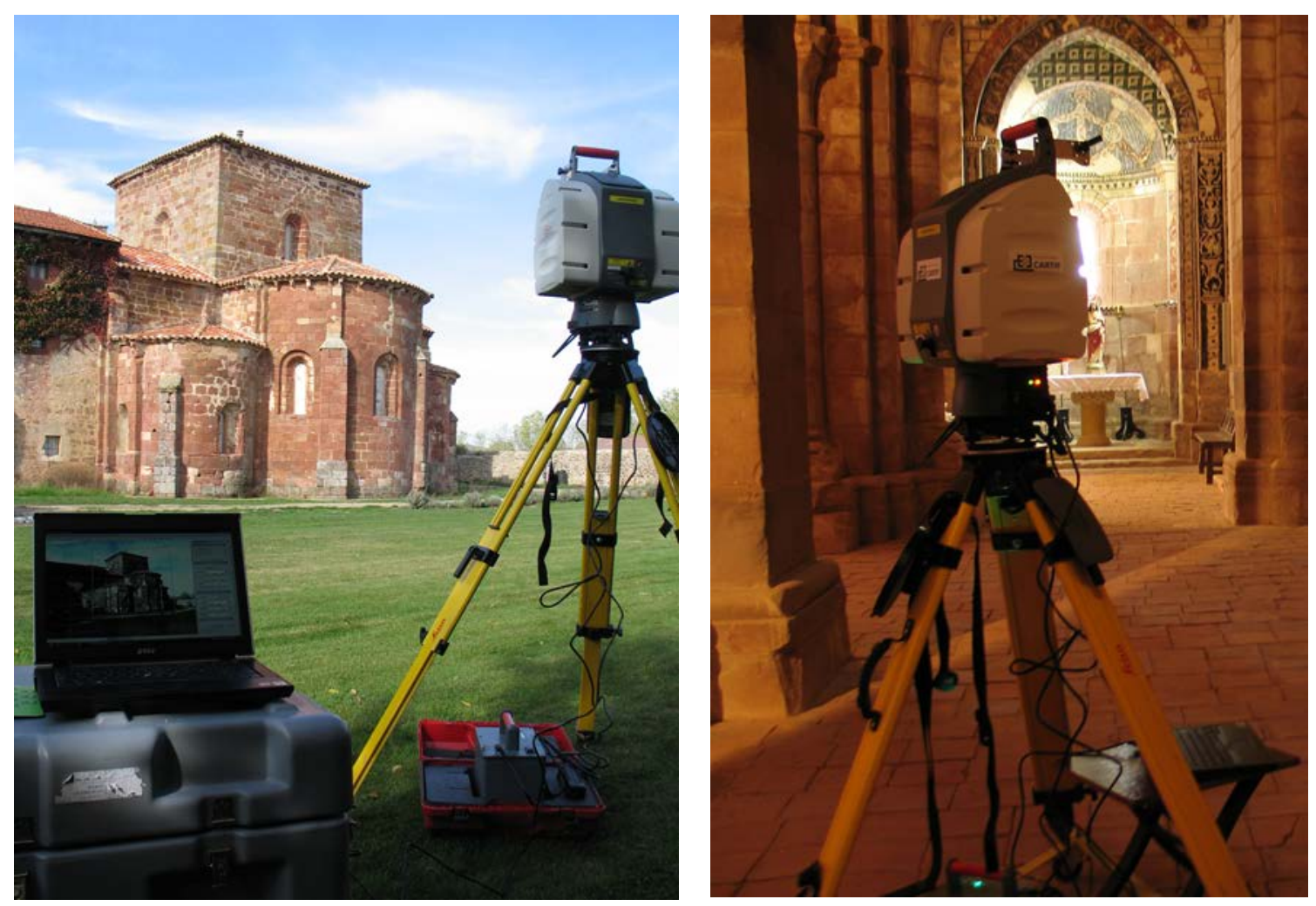

Figure 14: Scanning process: external and internal data collection.

Source: adapted from (Lerones et al., 2014). 

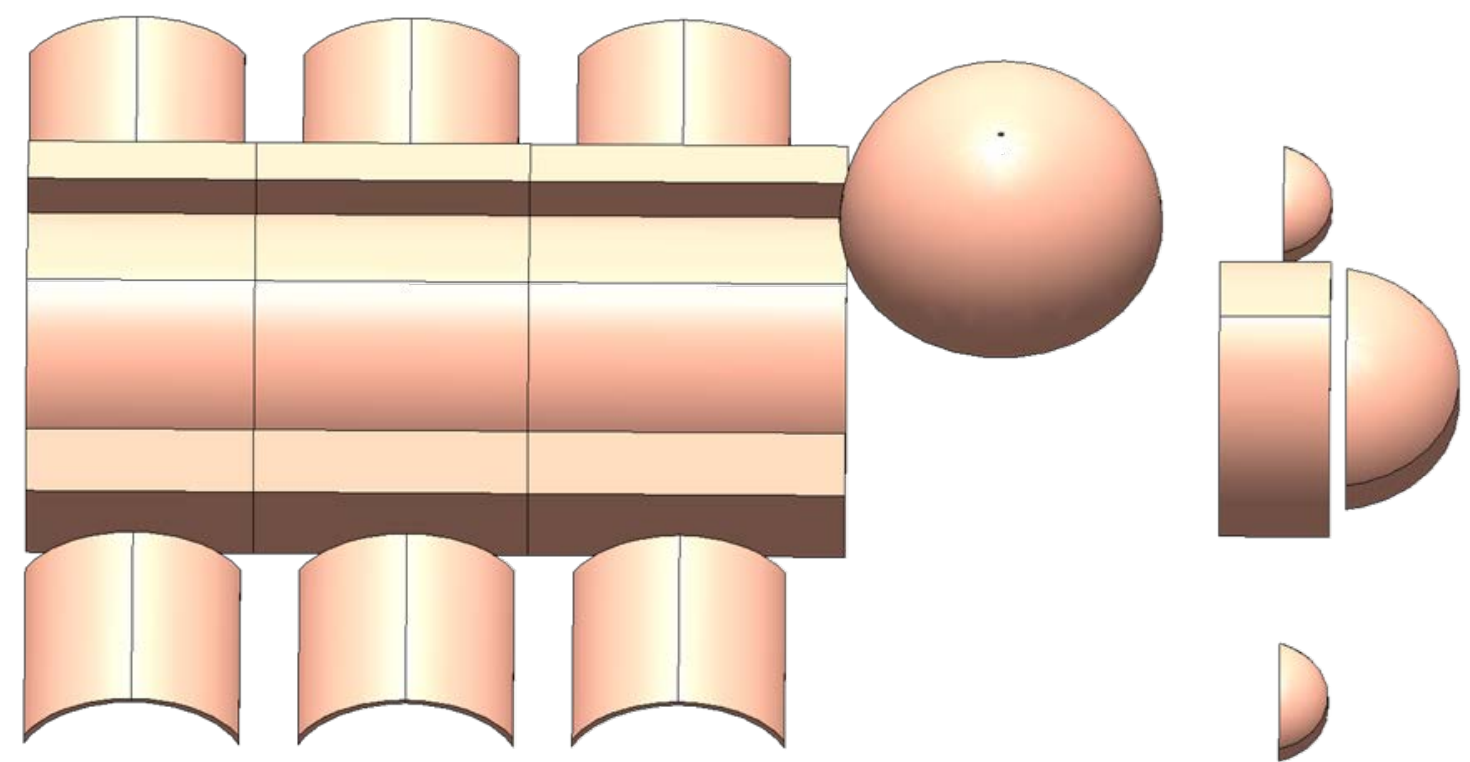

A)
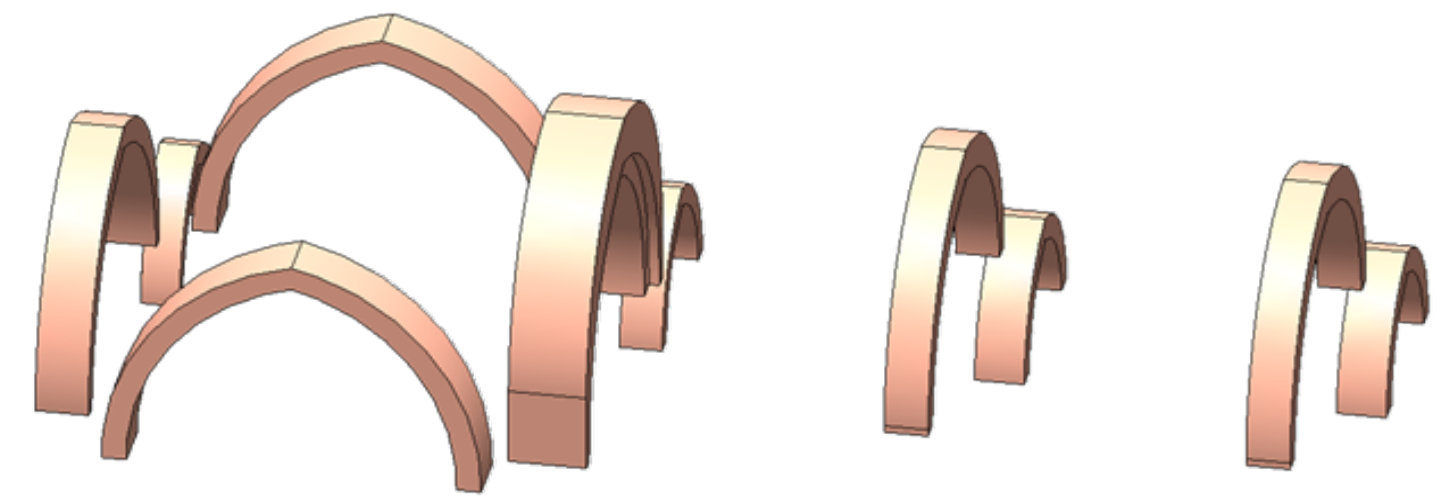

$\pi$
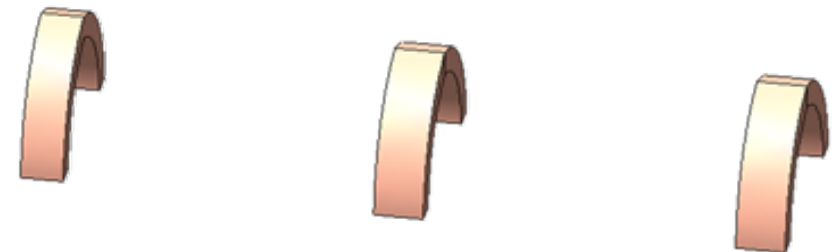

B)

Figure 15: A) Set of vaults and domes created. B) Set of arcs.

Source: Own figures. 


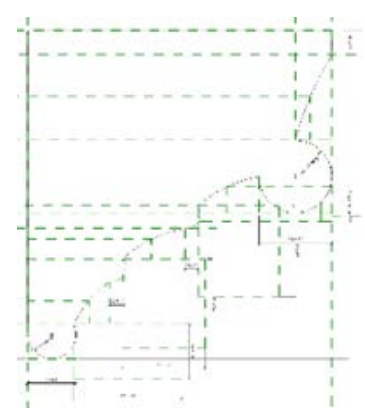
Reference
planes

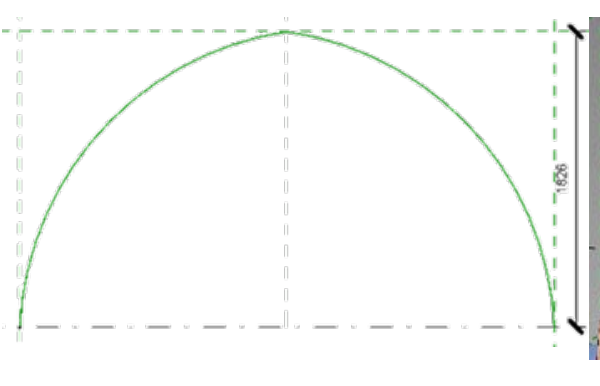

Reference lines
Solid geometry of the element

A)

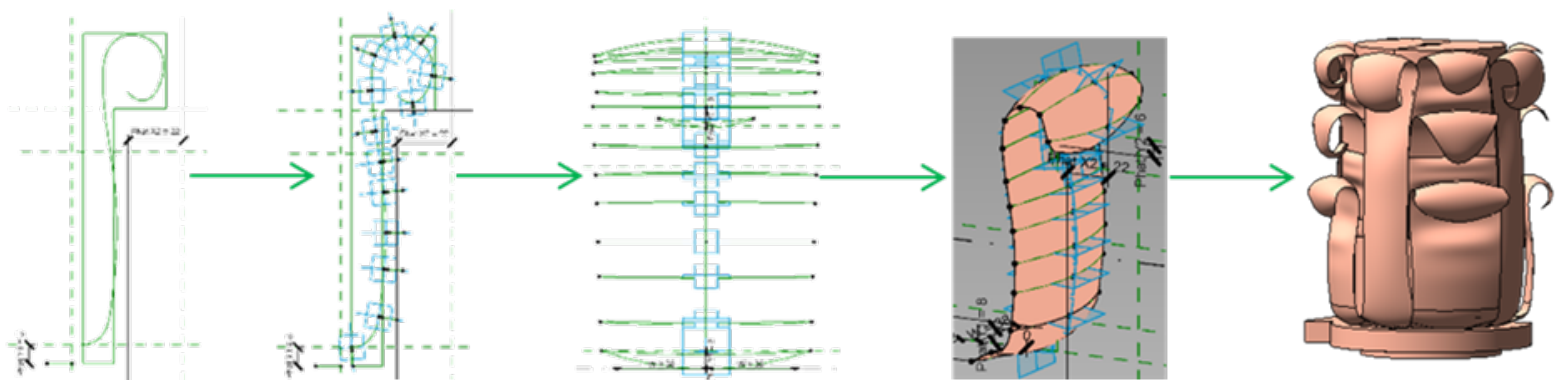

B)

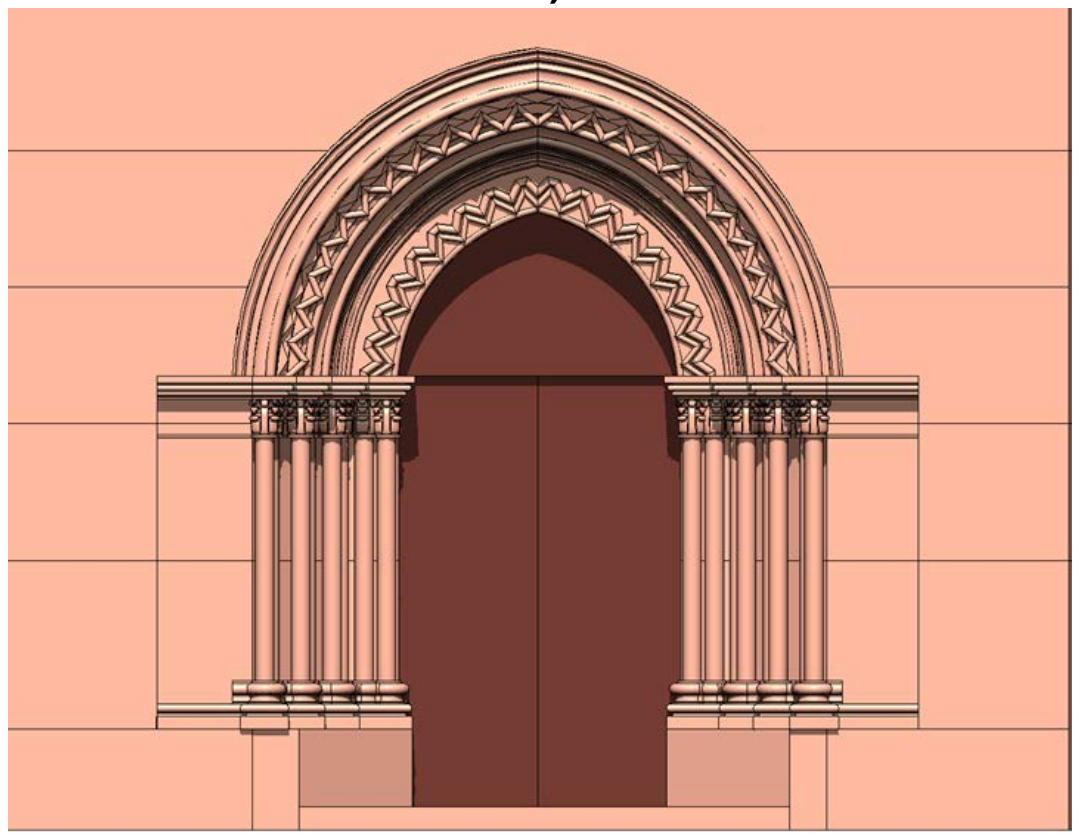

C)

Figure 16: A) Construction sequence of an uneven surface: creation of one of the arches that crowns the main entrance. B) Construction sequence of one of the leaves that decorate the capital and the obtained result. C) Final result of the "Family Entrance" modeling.

Source: Own figures. 


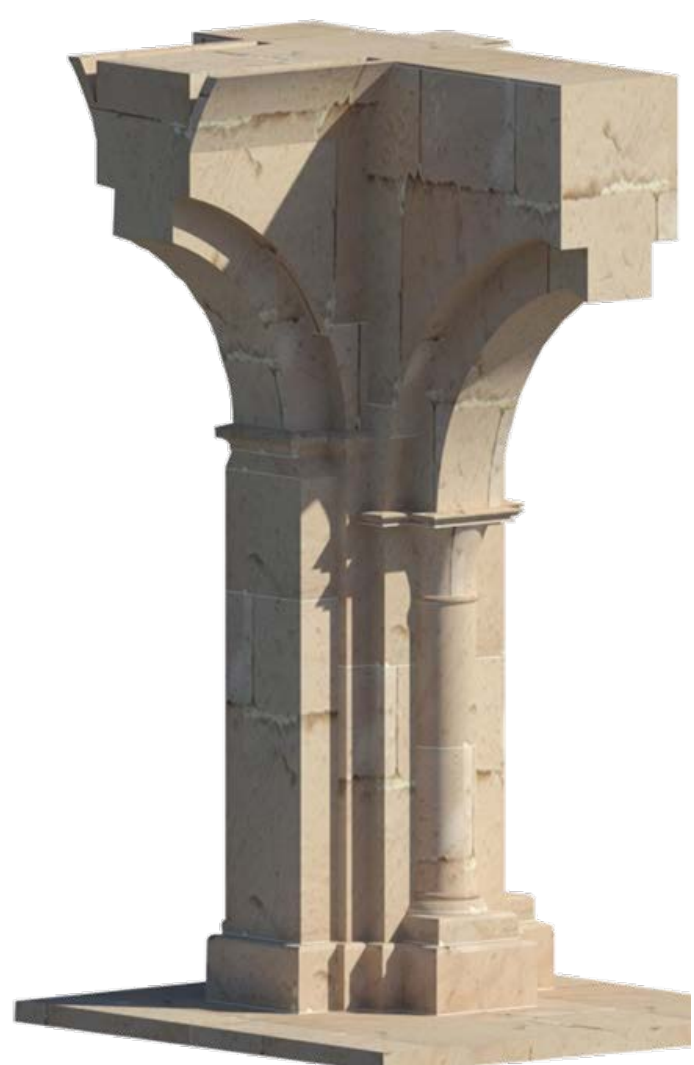

A)

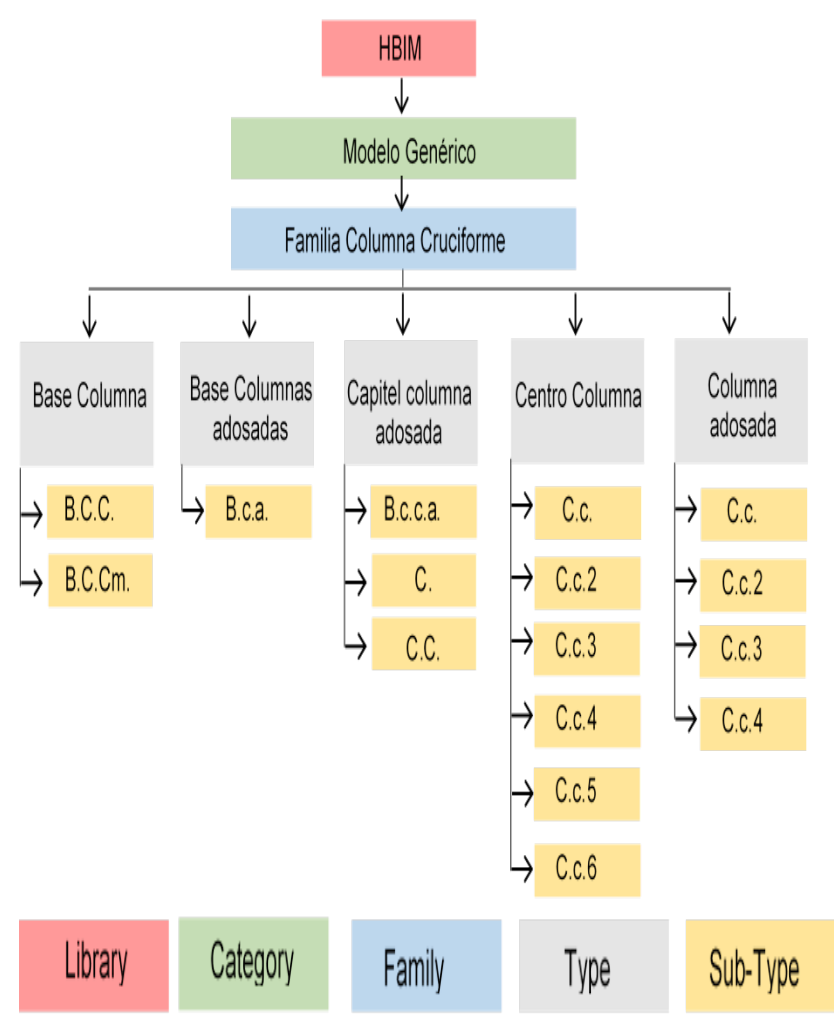

B)

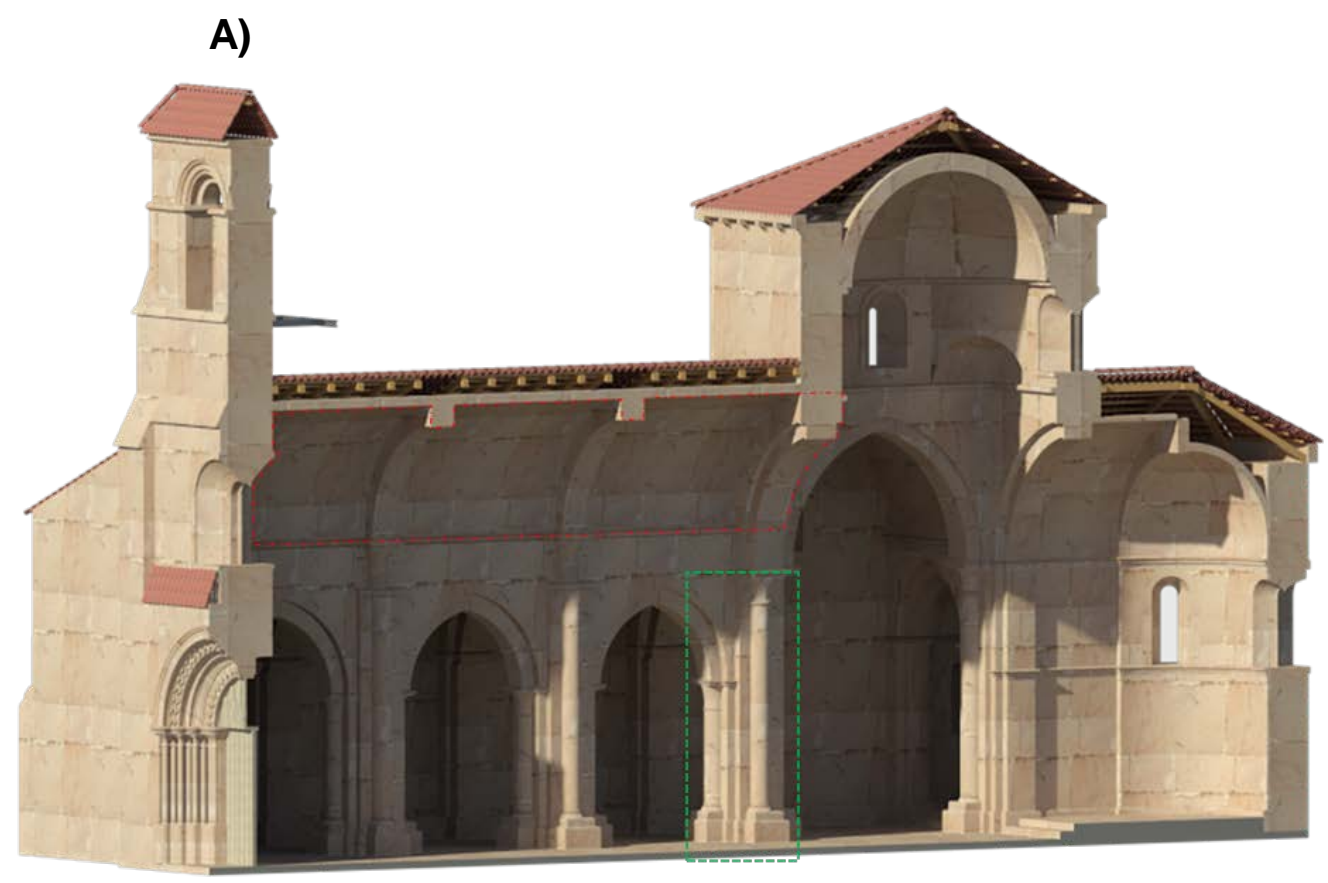

C)

Figure 17: A) Cruciform column. B) Types and sub-types that make up the modeled families. C) Longitudinal section, where the cruciform pillars with semicolumns and barrel vaults separated by arches that cover the central nave.

Source: Own figures. 


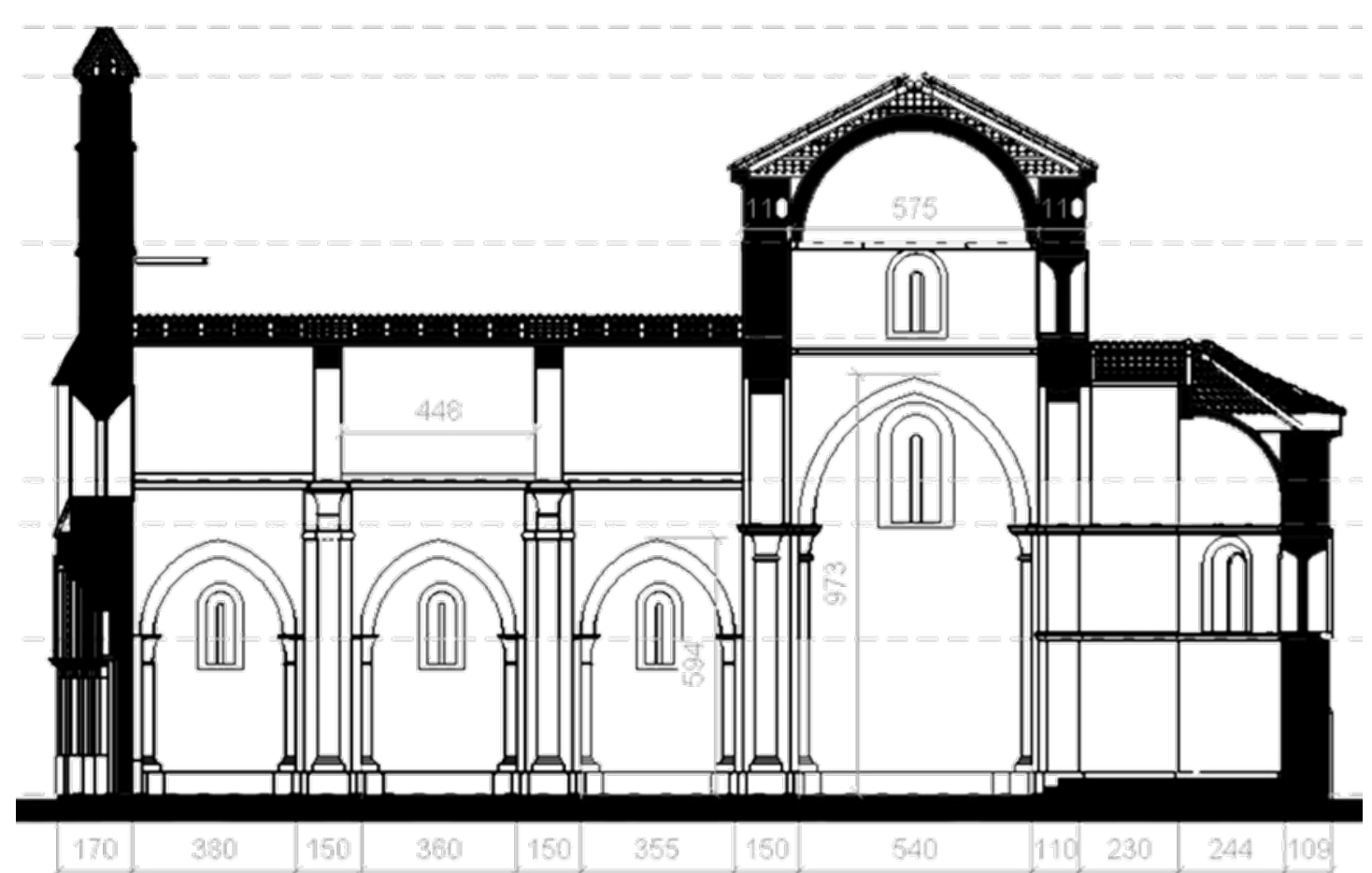

A)

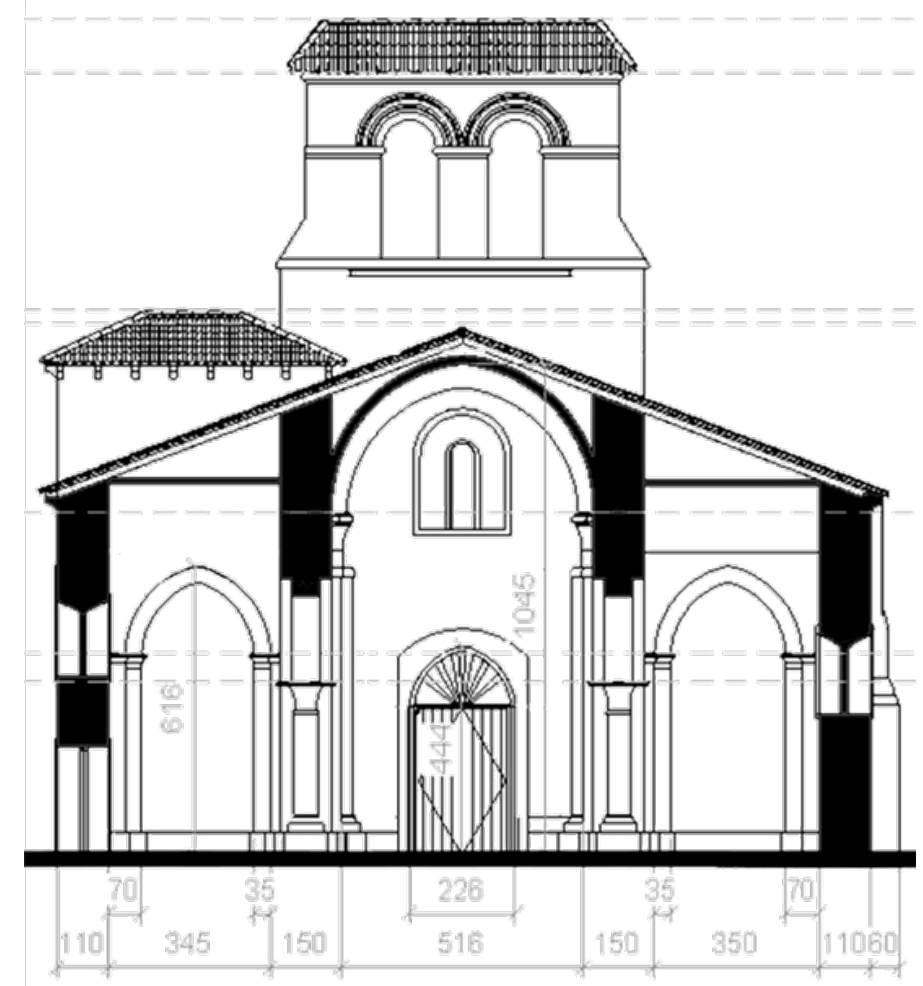

B)

Figure 18: A) Longitudinal section of the church. B) Cross section of the church. Some dimensions are shown in both sections.

Source: Own figures. 


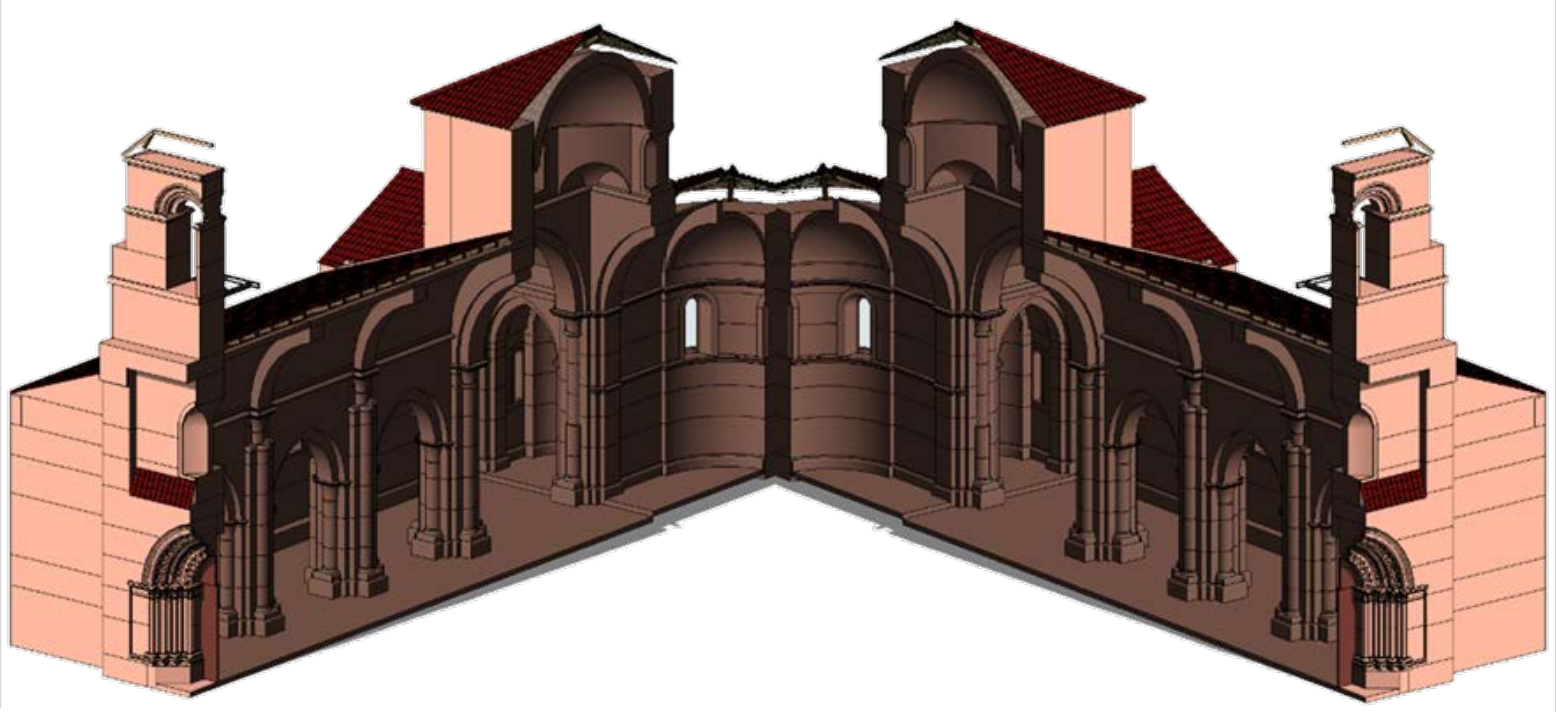

Figure 19: Final result: the complete church.

Source: Own figures. 